\title{
Lasers in Chemical Processing
}

\author{
J. I. Davis
}

Manuscript date: April 15, 1982

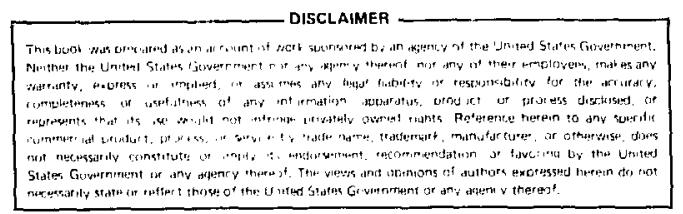

\section{LAWRENCE LIVERMORE LABORATORY University of California $\bullet$ Livermore, California $\bullet 94550$}




\title{
Lasers in Chemical Processing*
}

\begin{abstract}
The high cost of laser energy is the crucial issue in any potential laser-processing application. It is expensive relative to other forms of energy and to most bulk chemicals. We show those factors that have previously frustrated attempts to find commercially viable laser-induced processes for the production of materials. Having identified the general criteria to be satisfied by an economically successful laser process and shown how these imply the laser-system requirements, we present a status report on the uranium laser isotope separation (LIS) program at the Lawrence Livermore National Laboratory (LLNL).
\end{abstract}

\section{Introduction}

We present a brief summary of soine potential applications of lasers in chemical processing in Fig. 1.

The first one is isotope separation, on which we have expended the most effort. Generally speaking, based on current technology, the prod- uct must have a value of something like $\$ 10 / \mathrm{kg}$ before lasers would be useful in that application. We will discuss this cost in detail later.

The next item is the cleanup of radioactive waste. Since there are a large number of isotopes generated in the fission process, this application

\begin{tabular}{|c|c|}
\hline Application & Economic Potential \\
\hline 1. Isotope separation & $\begin{array}{l}\text { - Demands today a high-value product } \\
\geq \$ 10 / \mathrm{kg}\end{array}$ \\
\hline 2. Cleanup of radioactive waste & $\begin{array}{l}\text { - Extremely high payoff if, and only if, } \\
\text { a fully integrated reprocessing cycle is } \\
\text { realized, including military } \\
\text { applications. }\end{array}$ \\
\hline 3. Trace impurity removal & $\begin{array}{l}\text { - Cannot alone support technology de- } \\
\text { velopment but will be major spinoff }\end{array}$ \\
\hline 4. Selective chemical reactions & $\begin{array}{l}\text { Demands net gain in reaction (no. } \\
\text { particles/no. photons) } \gg 1\end{array}$ \\
\hline $\begin{array}{l}\text { 5. Photochemical activation or dissociation } \\
\text { of gases }\end{array}$ & $\begin{array}{l}\text { - Potential high leverage in many } \\
\text { applications (e.g., reactive etching, } \\
\text { coatings) }\end{array}$ \\
\hline 6. Control of combustion particulates & $\begin{array}{l}\text { Will probably happen slowily as a } \\
\text { spinoff }\end{array}$ \\
\hline 7. Crystal and powder chemistry & - Unique but interesting \\
\hline 8. Laser-induced biochemistry & $\begin{array}{l}\text { - Inevitable but a decade at least before } \\
\text { some clarification }\end{array}$ \\
\hline
\end{tabular}

Figure 1. Potential applications of lasers in chemistry.

\footnotetext{
This was prepared as an invited talk for both the American Institute of Chemical Engineers, 1982 Winter Meeting, Orlando, FL, February 28 to March 3, 1982, and the 183rd American Chemical Society National Meeting, Las Vegas, NV, March 28 to April $2,1982$.
} 
can have extremely high payoff, especially if we are allowed to process materials for military applications.

The third item, trace impurity removal, can be of value, but it does not presently have a high enough benefit to support a full laser technology development. We would have to derive the technology from some other application, such as isotope separation.

Next, selective chemical reactions have had world-wide attention for the past decade. However, at present such applications are economically feasible only when the number of product particles generated by each photon is considerably in excess of unity. In the last year or two, German researchers ${ }^{l}$ produced vinyl chloride monomers with gains of more than 100. Thus in the future these kinds of reactions may be izconomic on a large scale.

The fifth item is photochemical activation or dissociation of gases. That has some high leverage in many areas, for example, reactive etching where one dissociates a molecule and causes a de- position on a substrate, either to etch a surface or to coat a surface. Coating large optics to produce the fine figure on the surface would be an application of this type.

The next item, control of combustion particulates, has been worked on at LLNL and other laboratories. One application explored at LLNL is the decomposition of hydrogen sulfide from exhaust stacks. It looks like an interesting application, but it needs further work to evaluate the economics.

The seventh item is crystal and powder chemistry. This can be done using very highpower high-intensity lasers such as those developed for laser fusion. This is a unique and interesting application and it may have some potential in the distant future.

The final item, laser-induced biochemistry, has been widely publicized and researchers (e.g., Ref. 2) have been able to do such things as unzip the DNA molecule and other interesting experiments. We believe-it is an inevitable application of lasers, but will probably be at least a decade before the field is clarified.

\section{Lasers in Traditional Applications}

Figure 2 shows a simplified picture of how lasers would be used in a photoprocess. Basically all we are doing is adding laser energy into some kind of process. We assume that the addition of the lase: energy is going to improve the ield $(\mathrm{kg}$ of piuduct per $\mathrm{kg}$ of feed). This will cost so many $\mathrm{MJ}$ of energy per $\mathrm{kg}$ of feed $(1 \mathrm{MJ}=0.28 \mathrm{kWh}$ ). The greatest barrier to adding this laser energy is usually its cost. If we cannot significantly improve the yield, then the added cost of the laser photon stream will make the process uneconomical.

To illustrate this cost impact for lasers, Fig. 3 summarizes the cost of laser energy compared to oil and electricity. Oil is about $0.5 \% / \mathrm{M}$. To crnvert that into electricity we lose about is füctor of 2 . This leads to a cost of about $14 / \mathrm{MJ}$, which is equivalent to $36 \mathrm{mils} / \mathrm{kWh}$. If the lasers were about $1 \%$ efficient, the electrical cost alone to run the laser would be about $\$ 1 / \mathrm{MI}$. It is not unreasonable to expect this from an efficient singleaperture laser. But when we pist together a complex lase: electro optical systern and meet all the lifecycle requirements, it is urrealistic to try to produce laser energy for $\$ 1 / \mathrm{M}$. It is most likely going to be about $\$ 10$ to $\$ 100 / \mathrm{MJ}$.

Figure 4 summarizes some simple facts about laser energy and why the costs are so high. The reason laser energy is expensive is that, from a physicist's point of view, it is highly degenerate energy. The photons are localized to a single cell in phase space and the frequency (or energy) of those phoions is essentially limited by the uncertainty principle. From an electrical en:zineer's point of view, we are dealing with a transformlimited pulse of energy. To illustrate the impact of this cost of laser energy, the simple calculation shown here assumes $\$ 10 / \mathrm{MJ}$ and that it takes about $1 \mathrm{eV}$ for each particle produced in some photochemical process. Thus, if one visible photon is required to interact with each particle in one inole of material having a molecular weight of $100 \mathrm{~g}$, this would lead to a cost of about $\$ 10 / \mathrm{kg}$ for the laser energy alone. Since bulk chemicals sell for about $\$ 1 / \mathrm{kg}$, ti:e cost barrier is already about a factor of 10 . The conclusion is that we must have a very expensive product, i.e., much in excess of $\$ 10 / \mathrm{kg}$, or we must achieve some net gain when the laser beam interacts with the medium. That is, it must interact with only a portion of the medium or in some way catalyze a reaction within the medium so that we are not using one laser photon for each product molecule or atom generated.

As the scale of the process increases, we can expect the overall unit cost to decrease, not only 


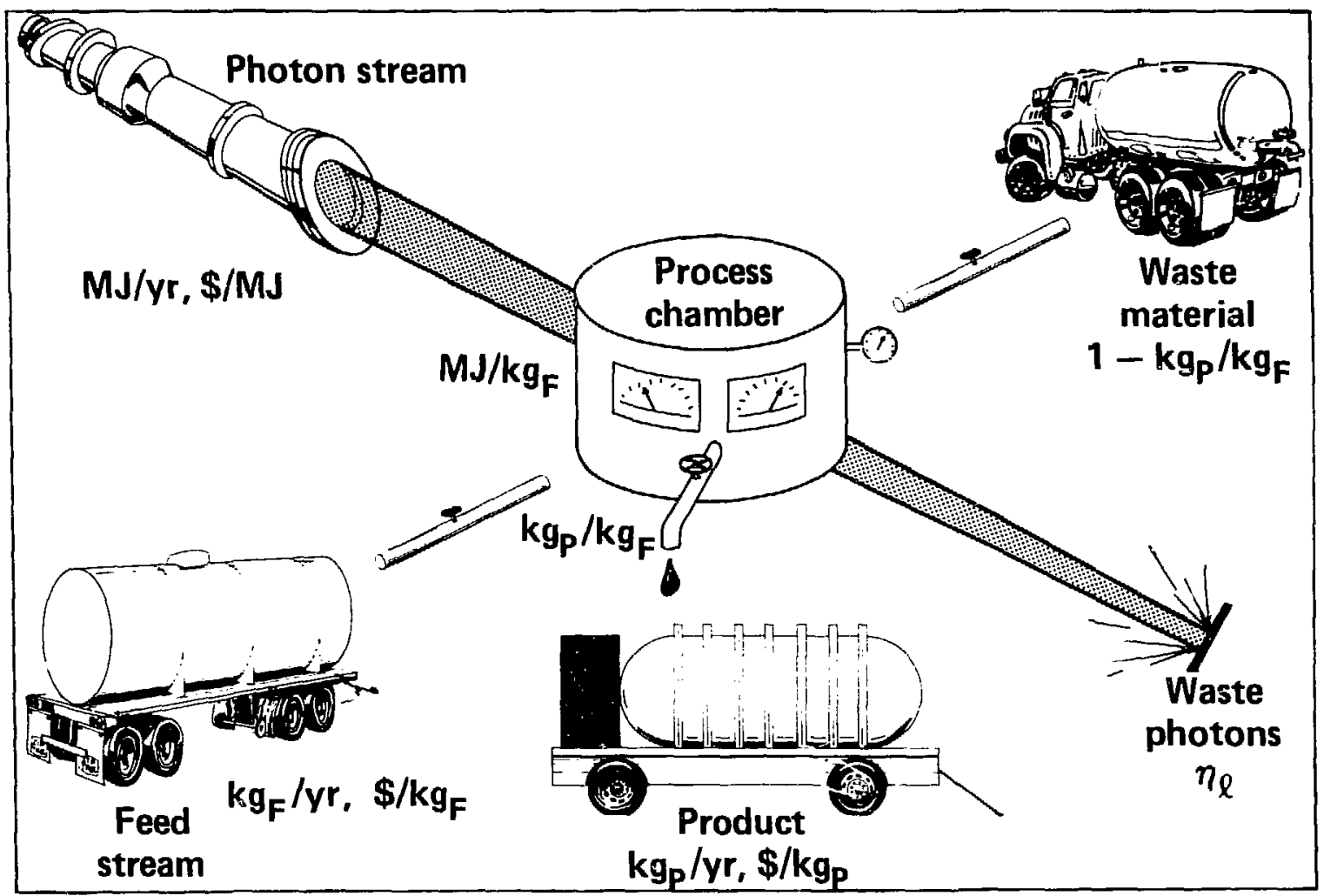

Figure 2. Elements of laser photoprocess.

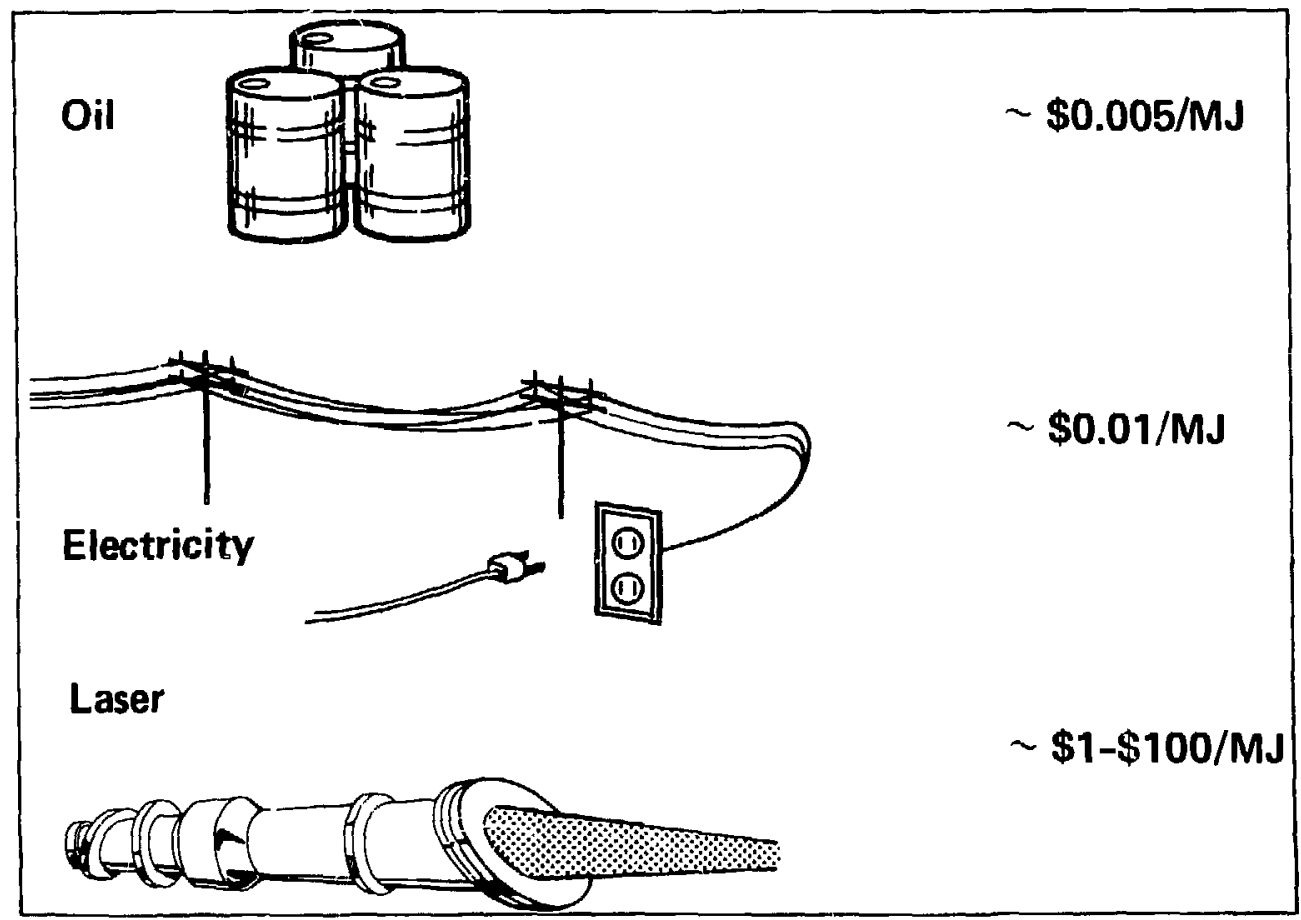

Figure 3. Comprison of energy costs. 
- Highly "degenerate" radiation ( coherence):

- Precise spatial control, diffraction limited, $\Delta \mathrm{k} \cdot \Delta \mathrm{x} \sim 1$

- Precise frequency control, transform limited, $\Delta \nu \cdot \Delta t \sim 1$

- Laser energy is expensive (1-100 \$/MJ):

$$
\frac{1 \mathrm{eV}}{\text { particle }} \times \frac{1.6 \times 10^{-19} \mathrm{~J}}{\mathrm{eV}} \times \frac{10^{-5} \$}{\mathrm{~J}} \times \frac{6 \times 10^{23} \text { particles }}{\text { mole }} \times \frac{1 \mathrm{~mole}}{0.1 \mathrm{~kg}} \approx \frac{10 \$}{\mathrm{~kg}}
$$

But typical bulk chemica!s sell for $\sim \frac{1 \$}{\mathrm{~kg}}$

- Conclusion:

Must have an expensive product and/or achieve significant gain with laser interaction, utilizing highly selective interaction within material.

Figure 4. Some simple facts about laser energy and why it is so expensive.

for the material produced, but also for the laser energy (MJ) generated. Figure 5 (a) shows this as a curve with $\$ / M$ J decreasing as a function of an increasing number of $\mathrm{M}$ J produced. A similar decrease [Fig. 5 (b)] occurs in the $\$ / \mathrm{kg}$ of product as a function of increasing total $\mathrm{kg}$ of product per year. Most bulk chemicals are shown in the lower right-hand corner of Fig. 5 (b). The distributed points for a wide variety of chemicals are illustrative of the results that were derived from a JASON study of several years ago. ${ }^{3}$ Figure 5 (b) also shows where light-water-reactor (LWR) fuel

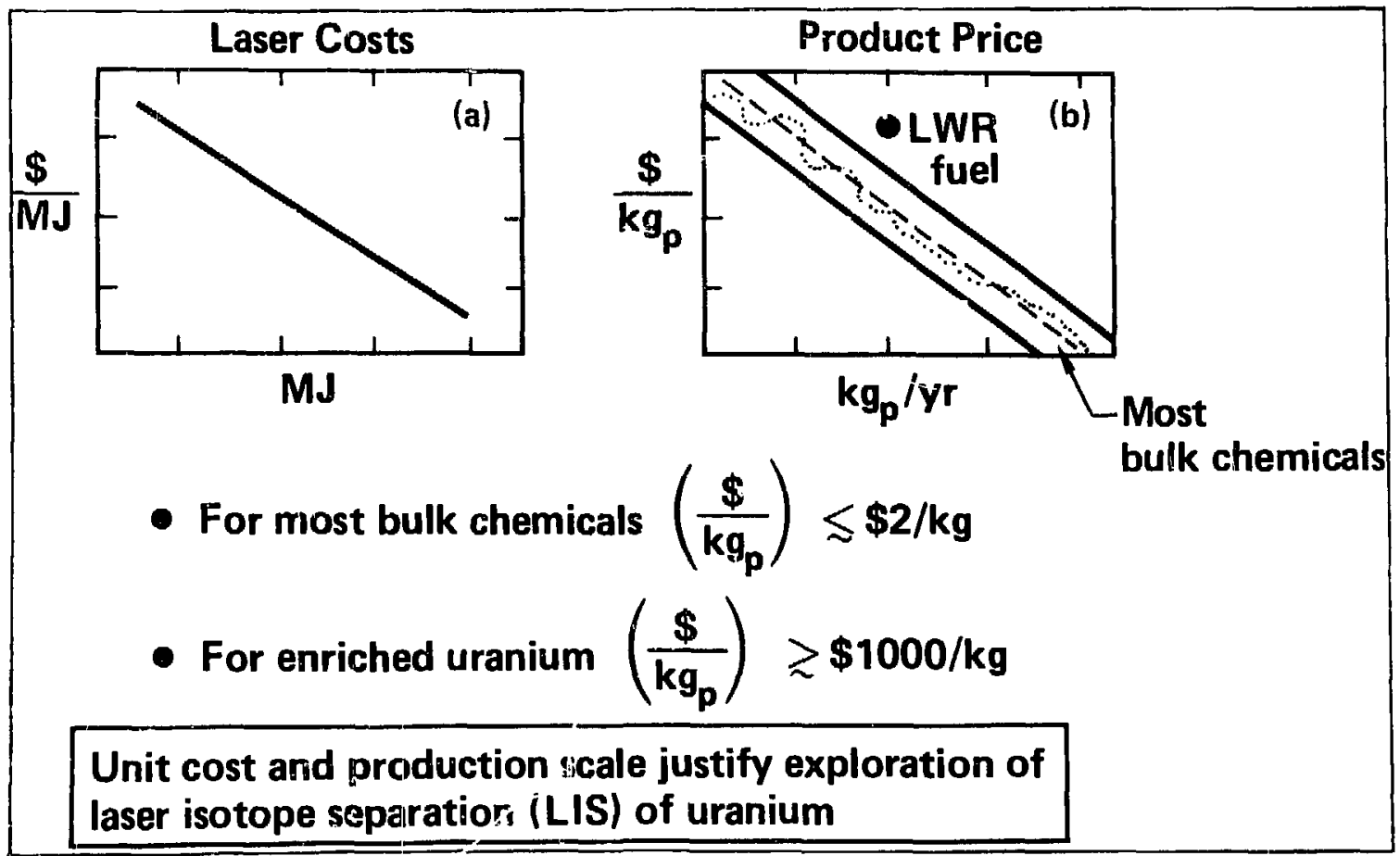

Figure 5. Economies of scehing. 
would fall and shows the relative cost for enriched uranium -(to fuel these light-water reactors) ':ompared to the cost of most tulk chemicals. This unit cost alone for enriched uranium would justify the exploration of the laser isotope separation (LIS) of uranium.

\section{laser Isotope Separation of Uranium}

The LIS of uranium demonstrates the general problem of applying lasers to materials processing. In addition to low urit cost, there are several other factors that need to be explored before launching a project of this type. These will be explained before giving the final justification for this effort.

The next aspeci is the market criteria, i.e., what considerations should we give to the existing technologies and the existing marketplace for producirig a product. Figure 6 (a) shows the $\$ / \mathrm{kg}$ product in capitril cost vs the $\$ / \mathrm{kg}$ product in operating cost. The dashed line shows the constant $\left(C_{1}\right)$ cost-of-projuct line. Depending on the type of process, this can be more operating cost or more capital cost. The case shown is dominated by operating cost. The solid line represents a hypothetical new process having a lower product $\cos t\left(C_{2}\right)$. The question is, even with this lower unit cost per $\mathrm{kg}$ product, what is the likelihood of capturing new capacity or displacing existing capacity? If the old process has an operating cost lower than the capital cost of the new process, then there is no way the old process can be displaced. That's because the old process only has to pay the operating cost to stay in business. Thus the way to displace the existing capacity is to have a capital cost that is certainly below the operating cost of the old process. In competing for new capacity, this is not the case. The capital cost could exceed the operaing cost of the old process. This issue of capital cost is summarized in Fig. 6 (b),

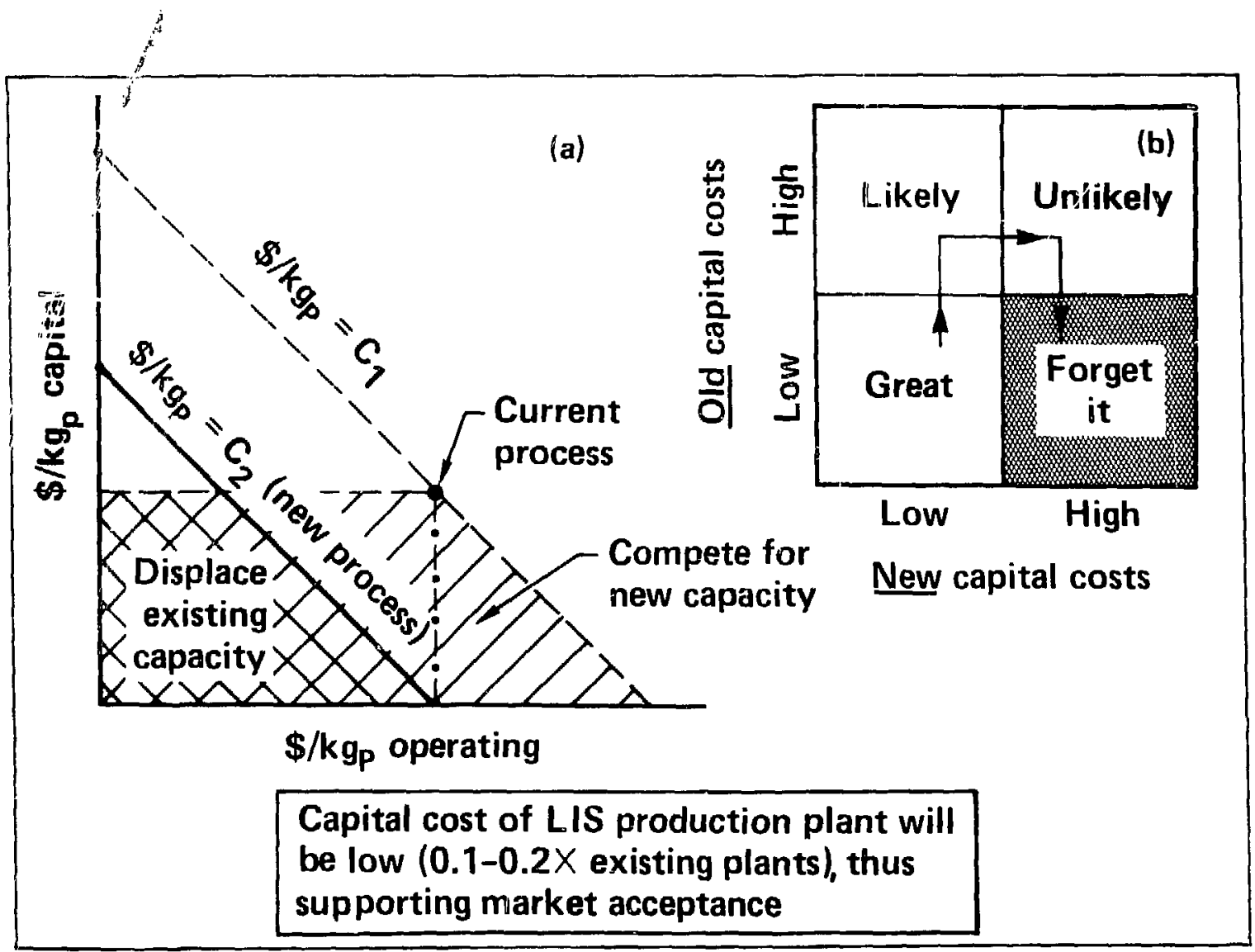

Figure 6. Market criteria for LIS process acceptance. 


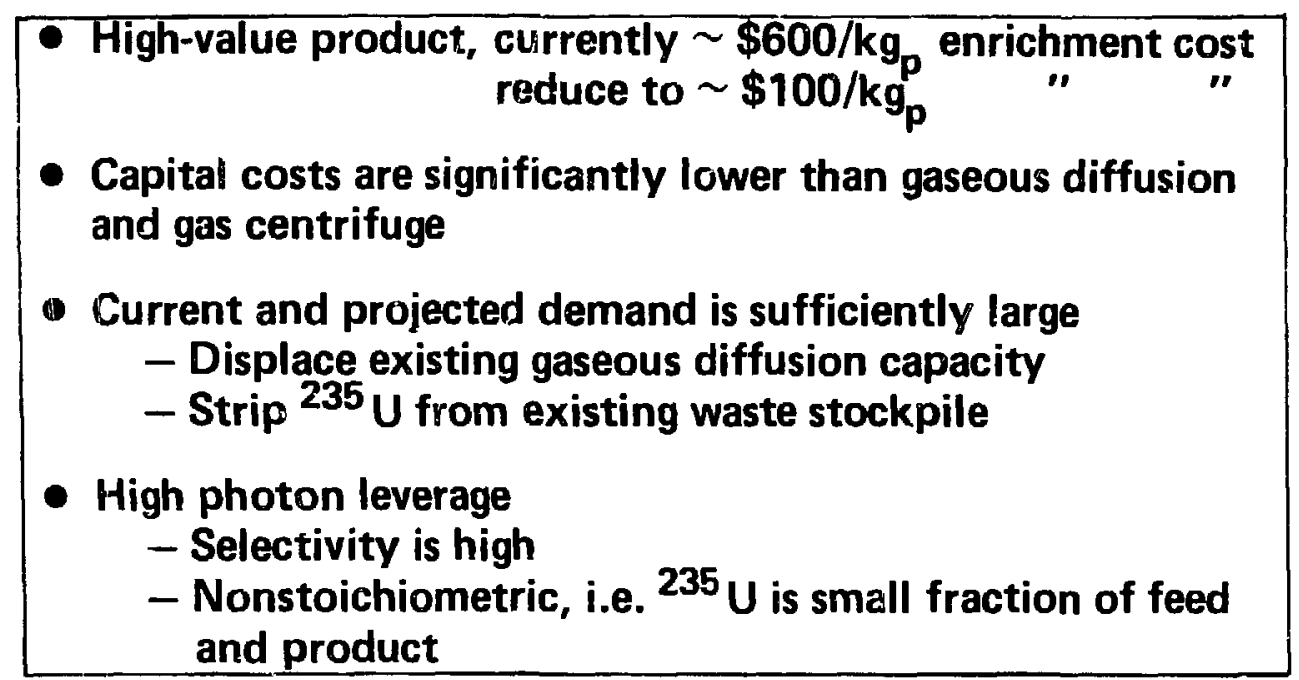

Figure 7. Reasons for AVLIS of uranium.

showing the likelihood of displacing old capacity as a function of the capital cost of the old process vs capital cost of the new process. If the capital costs of both processes were both low, then there would be nothing to protect in the old process, i.e., shutting down the plant and dismantling it would not be throwing away a large investment. Thus it is very likely that one could take over that capacity from the old process. Replacing an old high-capital-cost process with a new low-capitalcost process is likely. If they are both high capital cost, it is less likely. If the new process has a high capital cost and the old process has a low capital cost, then we can virtually forget that application. It is not likely that someone is going to trade new high capital cost for an old relatively high operating cost. In the case of our LIS process, we estimate a capital cost per new plant of somewhere between 10 and $20 \%$ of an existing gaseousdiffusion plant, so it is quite likely that we could penetrate the market on the basis of the capitalcost factor.

Figure 7 summarizes briefly why we believe the atomic-vapor laser isotope separation (AVLIS) of uranium is viable. We have a high-value product. Some $\$ 600 / \mathrm{kg}$ of product is required in enrichment at present and we believe we can reduce that to about $\$ 100 / \mathrm{kg}$. Our capital cost is significantly lower than gaseous diffusion and gas centrifuge. Thus we believe we can displace the existing gaseous-diffusion capacity. Furthermore, we feel that the demand for new capacity is adequate to justify development of our technology. We also believe we can strip the ${ }^{235} \mathrm{U}$ in the current waste stockpile produced by gaseous-diffusion plants. Another feature of our process is that it has very high selectivity and this allows the laser beam to interact with only a small fraction of the material processed through a machine. That is, the laser beams photoionize only ${ }^{235} \mathrm{U}$ and not ${ }^{238} \mathrm{U}$ because of this extremely high selectivity.

Selectivity is extremely important in laser processes and especially in evaluating the contribution the laser system makes to the overall cost of the process. Figure 8 introduces some of the terminology of this field. We use two basic process parameters that we call the stripping efficiency and the nonselective pickup. The stripping efficiency $\eta_{\mathrm{a}}$ is the fraction of the species " $\mathrm{a}$ " in the throughput stream that is photoselected and collected as product. The nonselective pickup $\phi$ is the fraction of the throughput stream picked up on the product collector at the feed assay. In other words, it is that fraction of the throughput stream that goes into the product stream that has not been influenced by the laser light. We will now show how these parameters compare with the conventional separation terminology used in the enrichment industry. Figure 9 summarizes these in terms of the following parameters:

- $\alpha$, the ratio of product to iails assay.

- $\beta_{1}$, the ratio of product to feed assay.

- $\beta_{2}$, the ratio of the feed to tails assay.

- $\theta$, the cut, i.e., the fraction of the material removed from the throughput stream.

- $\eta$, the yield in conventional terminology, i.e., the fraction of the species of interest that goes into the product stream. 


\begin{tabular}{|l|c|l|}
\hline Term & Symbol & \multicolumn{1}{c|}{ Physical Meaning } \\
\hline Stripping efficiency & $\eta_{\mathrm{a}}$ & $\begin{array}{l}\text { Fraction of species 'a' in the throughput } \\
\text { stream that is photoselected and collected } \\
\text { as product }\end{array}$ \\
$\begin{array}{l}\text { Nonselective } \\
\text { pickup }\end{array}$ & $\phi$ & $\begin{array}{l}\text { Fraction of throughput stream picked up } \\
\text { on product collector at the feed assay }\end{array}$ \\
\hline
\end{tabular}

Figure 8. LIS terminology.

This shows how these parameters relate to our stripping efficiency and nonselective pickup. Two types of uranium-enrichment processes are illustrated in Fig. 9. One has very high selectivity, which means that the $\eta_{5}$ (the $\eta$ of ${ }^{235} U$ ) is very large compared to $\eta_{8}$ (the $\eta$ of ${ }^{238} \mathrm{U}$ ). The second process has a negligible nonselective pickup and arbitrary selectivity. These relations show the general connection between the two processes. Note that these two processes will end up having

\begin{tabular}{|c|l|l|l|}
\hline$\alpha$ & \multicolumn{1}{|c|}{ Exact Expression } & $\begin{array}{c}\text { High Selectivity } \\
\eta_{5}>>\eta_{8}\end{array}$ & $\begin{array}{c}\text { Negligible Nonselective } \\
\text { Pickup: } \\
\phi \rightarrow 0\end{array}$ \\
\hline $\begin{array}{c}\frac{1}{\phi} \frac{\eta_{5}}{1-\eta_{5}}+1 \\
\frac{1}{\phi} \frac{\eta_{8}}{1-\eta_{8}}+1\end{array}$ & $\frac{1}{\phi} \frac{\eta_{5}}{1-\eta_{5}}+1$ & $\frac{\eta_{5} /\left(1-\eta_{5}\right)}{\eta_{8} /\left(1-\eta_{8}\right)}$ \\
\hline$\beta_{1}$ & $\frac{\frac{\eta_{5}}{\phi}+\left(1-\eta_{5}\right)}{\eta_{8}+\left(1-\eta_{8}\right)}$ & $\frac{\eta_{5}}{\phi}+\left(1-\eta_{5}\right)$ & $\frac{\eta_{5}}{\eta_{8}}$ \\
\hline$\beta_{2}$ & $\frac{1-\eta_{8}}{1-\eta_{5}}$ & $\frac{1}{1-\eta_{5}}$ & $\frac{1-\eta_{8}}{1-\eta_{5}}$ \\
\hline$\theta$ & $\begin{array}{l}\phi+\eta_{8} x_{8}(1-\phi) \\
+\eta_{5} x_{5}(1-\phi)\end{array}$ & $\phi+\eta_{5} x_{5}(1-\phi)$ & $\eta_{8}+\chi_{5}\left(\eta_{5}-\eta_{8}\right)$ \\
\hline$\eta$ & \begin{tabular}{l}
$\eta_{5}+\left(1-\eta_{5}\right) \phi$ \\
\hline
\end{tabular} & $\eta_{5}+\left(1-\eta_{5}\right) \phi$ & $\eta_{5}$ \\
\hline
\end{tabular}

Figure 9. Separation terminology. 


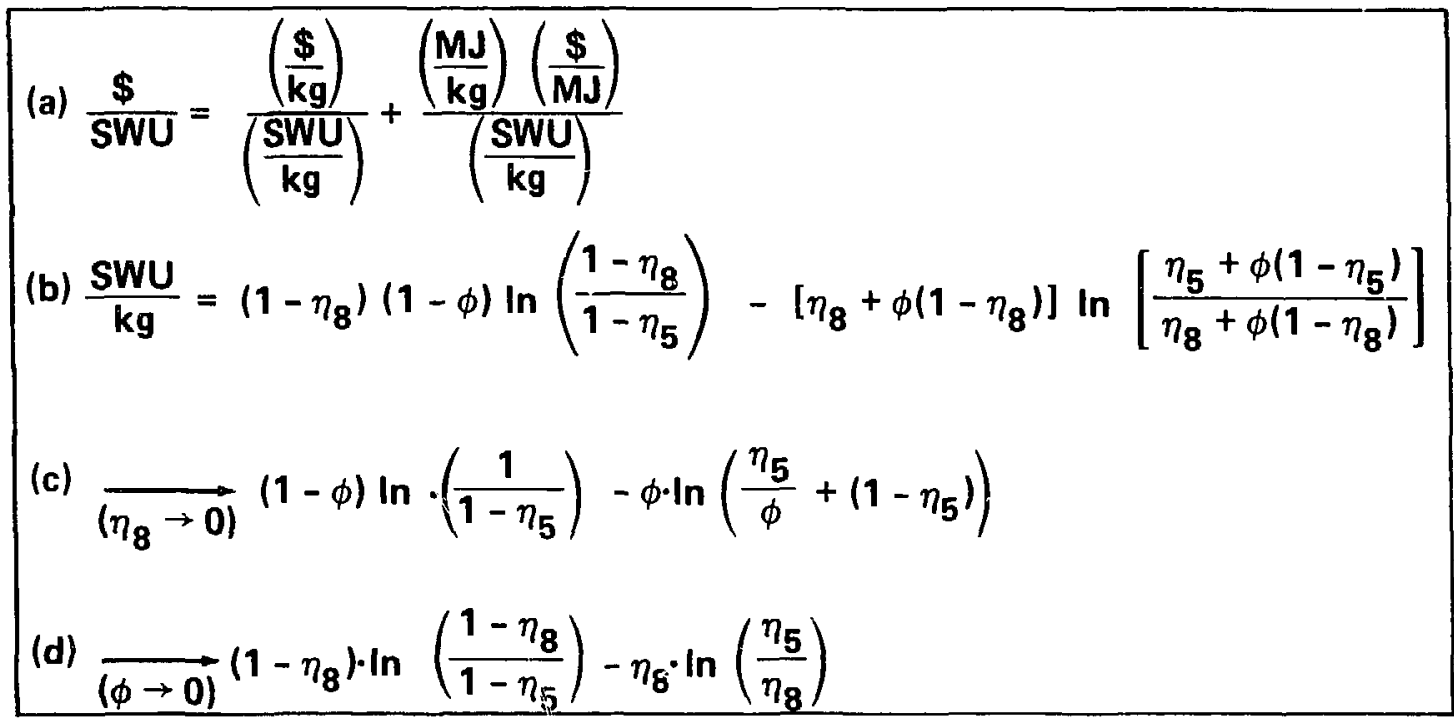

Figure 10. Cost of separative work.

the same separation parameters under certain conditions, even though one has very high selectivity and the other may not. For example, if the $\eta_{5}$ of the process with very low nonselective pickup were set equal to the yield of the high-selectivity process and if $\eta_{8}$ of that same process were set equal to the nonselective pickup of the highselectivity process, all of the separation parameters would be identical. Thus we see that a high-selectivity process can be equivalent to a process with arbitrarily low selectivity. To show the significance of this, Fig. 10 illustrates how the cost of separative work depends on several parameters.

Figure 10 (a) shows \$/separative work unit (SWU) and shows it broken out into two major terms. The $\$ / \mathrm{kg}$ in the first term is the dollars required to process the $\mathrm{kg}$ of material through the machine where it is illuminated by the lasers. Then the basic yield of the process or the SWU/kg being produced through that machine would be the denominator. Thus the first term gives the \$/SWU associated with just processing materials through the machine independent of the cost of laser irradiation. The second term consists of the specific amount of energy in MJ required to illuminate $1 \mathrm{~kg}$ of the material. This is multiplied by the dollars expended for each MJ of that energy. The $S W U / \mathrm{kg}$ common to both terms can be written out as shown in Fig. 10 (b) in its complete form. Figure 10 (b) then shows how that works out for the two types of processes described in
Fig.9. That is, one in which there is very little interaction of the laser beam with the ${ }^{238} \mathrm{U}$, which means $\eta_{8}$ going to zero [Fig. 10 (c)]. Figure 10 (d) describes a process where there is very little nonselective pickup. Once again these two expressions are identical under certain conditions, so that high selectivity is not critical to achieving high separative work per $\mathrm{kg}$. The piace where selectivity enters into this economics expression is in the total amount of specific energy required to irradiate $1 \mathrm{~kg}$ of vapor. This is illustrated in Fig. 11 , which shows the specific laser energy required. It is divided into three basic terms, i.e., the total energy entering the machine equals the energy absorbed by ${ }^{235} U\left(\varepsilon_{5}\right)$ plus the energy absorbed by ${ }^{238} \mathrm{U}\left(\varepsilon_{8}\right)$ plus the energy $\varepsilon_{\ell}$ that is exhausted from the machine, lost in the optics, or scattered. By simple manipulation these can be put in terms of stripping efficiencies. We can see that the expression in the box for the specific energy, $\mathrm{MJ} / \mathrm{kg}$, depends on the ratio of the photo energy to the particle mass. This is then multiplied by the various terms including the stripping efficiencies. The primary terms are the stripping efficiency of ${ }^{235} \mathrm{U}$ multiplied by the assay of ${ }^{235} \mathrm{U}$ plus the stripping efficiency of ${ }^{238} \mathrm{U}$ multiplied by the assay of ${ }^{238} \mathrm{U}$. The term $\left(1-\eta_{\ell}\right)$ in the denominator is simply the efficiency with which the photons are used in the photo-separation process.

One major conclusion can be drawn from this as illustrated in Fig. 12. High laser selectivity is not essential to achieve high SWU $/ \mathrm{kg}$. But high 
- The total energy, $\stackrel{\bullet}{*}$, consists of three terms:

$$
\varepsilon=\varepsilon_{5}+\varepsilon_{8}+\varepsilon_{\ell}
$$

\section{Where}

$$
\begin{aligned}
& \mathscr{E}_{5}=\text { energy absorbed by }{ }^{235} \mathrm{U} \text { species } \\
& \&_{8}=\text { energy absorbed by } 238 \mathrm{U} \text { species } \\
& \varepsilon_{\ell}=\text { energy lost in optical system plus exhausted from separator }
\end{aligned}
$$

Assuming efficient collection of photoselected particles:

$$
\frac{\mathrm{MJ}}{\mathrm{kg}}=\left(\frac{\epsilon}{\mathrm{m}}\right) \frac{\eta_{5} \chi_{5}+\eta_{8} \chi_{8}}{1-\eta_{\ell}}
$$

Where

$$
\begin{aligned}
& \frac{\epsilon}{\mathbf{m}}=\frac{\text { Photo energy }}{\text { Particle mass }} \\
& \eta_{\ell}=\text { fraction of input energy lost in optical system plus exhausted } \\
& \text { from separator. }
\end{aligned}
$$

Figure 11. Specific laser-energy requirements.

selectivity is essential to achieve low energy $/ \mathrm{kg}$. This will dominate the laser cost in the process. With all else being equi, an LIS process with low selectivity (using natural feed where ${ }^{235} \mathrm{U}$ is a fraction of a percent of the tota! amount of material passed through the machine) could require as much as 100 times the specific energy required in a high-selectivity process. One reason we chose the AVLIS process at LLNL is because of its very high selectivity. Another reason for choosing this process is that it applies to all heavy atoms and basically all actinides.

\section{High selectivity is not essential to achieve high SWU/kg}

\section{High selectivity is essential to achieve low $\mathrm{MJ} / \mathrm{kg}$}

All else being equal, an LIS process with low selectivity $\left(\frac{\eta_{5}}{\eta_{8}} x_{5} \ll \chi_{8}\right)$ will require $\sim 10^{2}$ more specific laser
energy than a high-selectivity $\left(\frac{\eta_{5}}{\eta_{8}} \chi_{5} \gg x_{8}\right)$ process.

Figure 12. LIS process selectivity. 


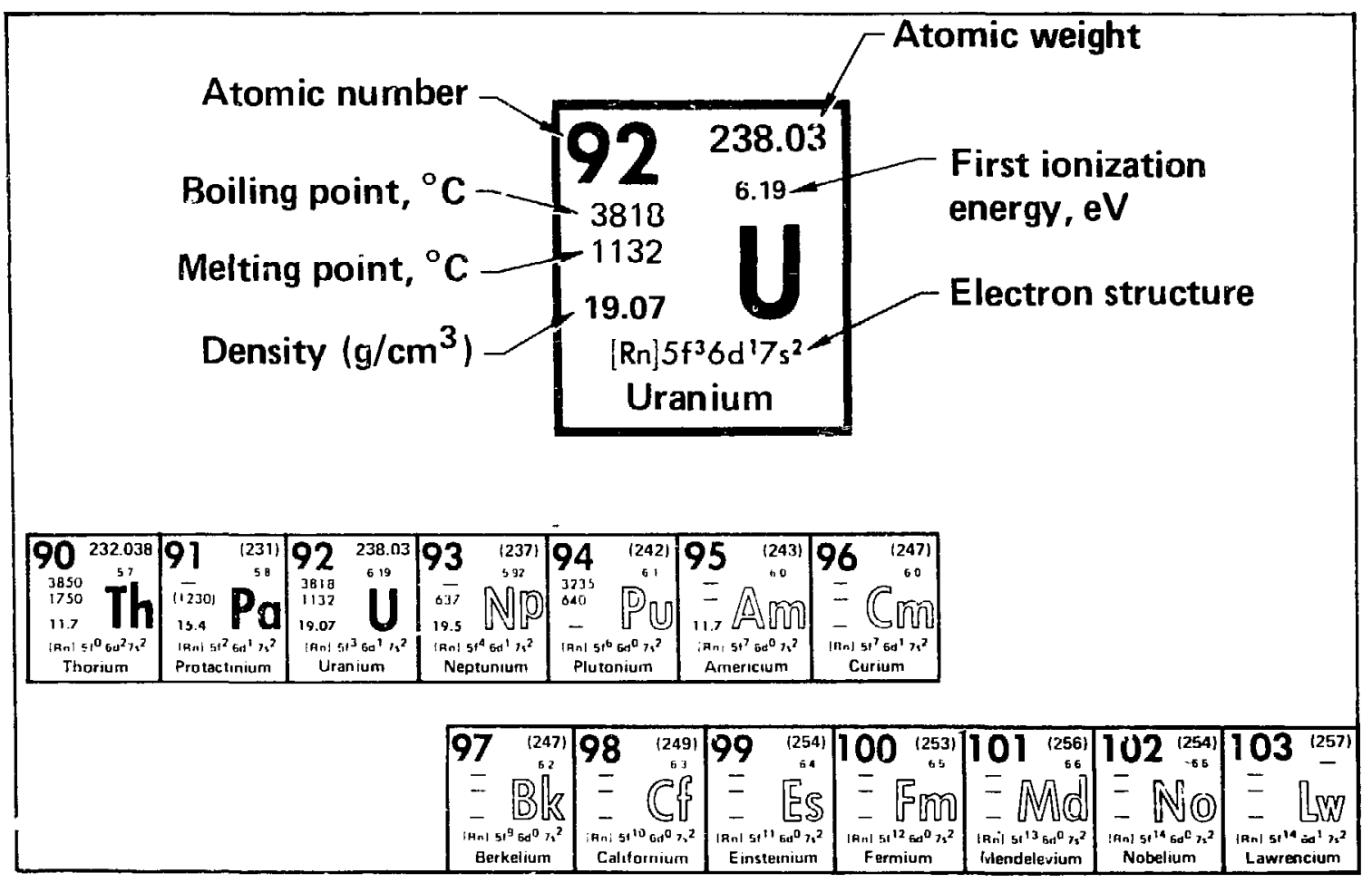

Figure 13. The actinides.

If we look at the portion of the periodic table that includes actinides (Fig. 13), they have one important feature in common. They all include $s$ electrons in their outermost electronic shell, so we can say a priori that there will be a large isctope shift in many optical transitions in these atoms. Since the s electrons always penetrate the core, we can expect that the volume effect of the nucleus will shift the electronic distributions and give significant isotope shifts.

Figure 14 shows the energy-level diagram for uranium, a typical actinide, showing at least a few of the low-lying states. The diagram shows that there is a collection of odd-parity states and a collection of even-parity states. Note that in going from the ground state to an even-parity state (involving an $s-p$ transition, which is a very strong dipole transition) we would require approximately $2 \mathrm{eV}$ or more. These states are shown in the fourth column of the collection of even-parity states. Such a transition a priori would have a large isotope shift. The pathway for taking the atom up from that position to its ionization limit could be traveled by either adding a 4-eV photon or adding two $2-\mathrm{eV}$ photons, etc. What we have chosen to do is to use three 2-eV photons to achieve the $6 \mathrm{eV}$ needed for ionization. We have also investigated processes using both two-photon and single-photon ionization.

Figure 14 is greatly simplified. If we were to expand it roughly 100 million times and look at a single optical transition in this system, we would find a lot of detailed structure. Figure 15 shows the hyperfine structure of a single transition going from the grourid state to $15,632 \mathrm{~cm}^{-1}$. These types of data have been taken on hundreds to thousaiids of optical transitions and are well characterized. Figure 16 shows one of the excited-state transitions with a resolution of about 1 part in $10^{8}$.

To surnmarize this spectroscopic information, there are three major processes we have explored. The types of laser technology we use to do the photoionization are shown in Fig. 17. The baseline process we have expended the most effort on is the three-photon process. The dashed lines show the ${ }^{238} \mathrm{U}$ transitions. We can achieve an isotope shift on all transitions, resulting in cur.ulative selectivities in excess of $10^{7}$. Similar experiments have been done for both two-step and one-step processes. 


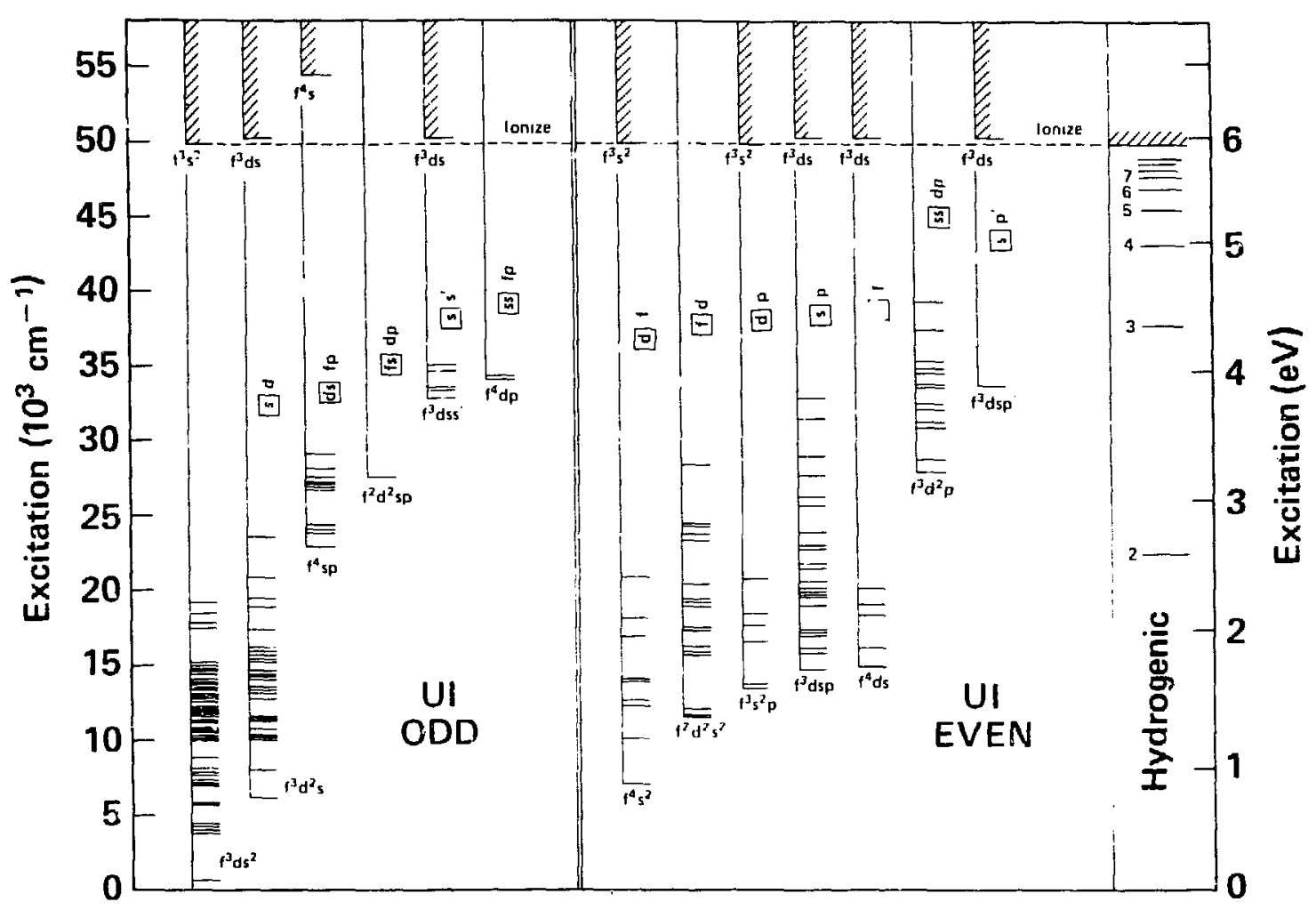

Figure 14. Typical actinide energy leyels using uranium as example.

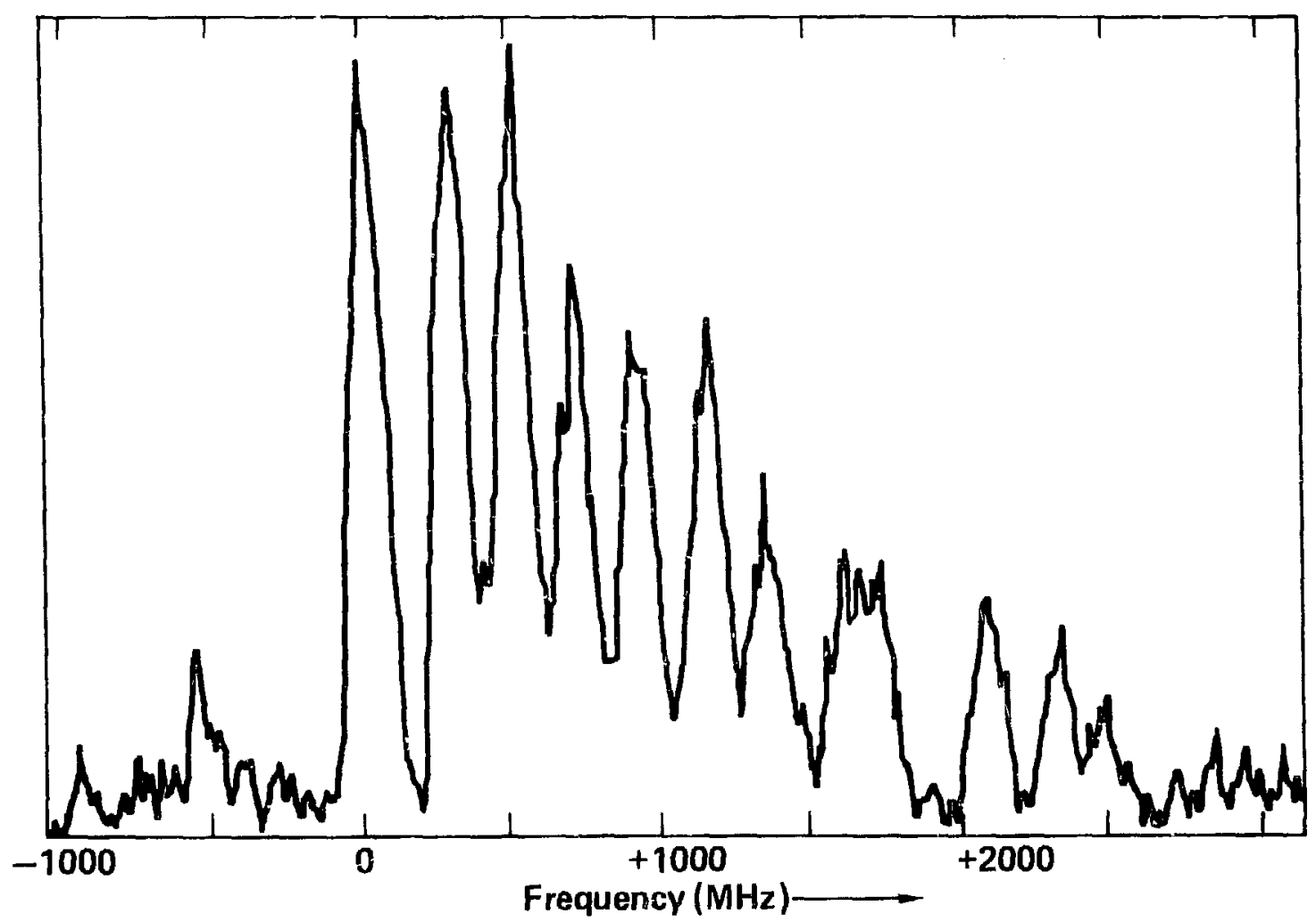

Figure 15. Hyperfine structure of $6395-\dot{\mathrm{A}}\left(0\right.$ to $\left.15,632 \mathrm{~cm}^{-1}\right)$ transition in ${ }^{235} \mathrm{U}$. 


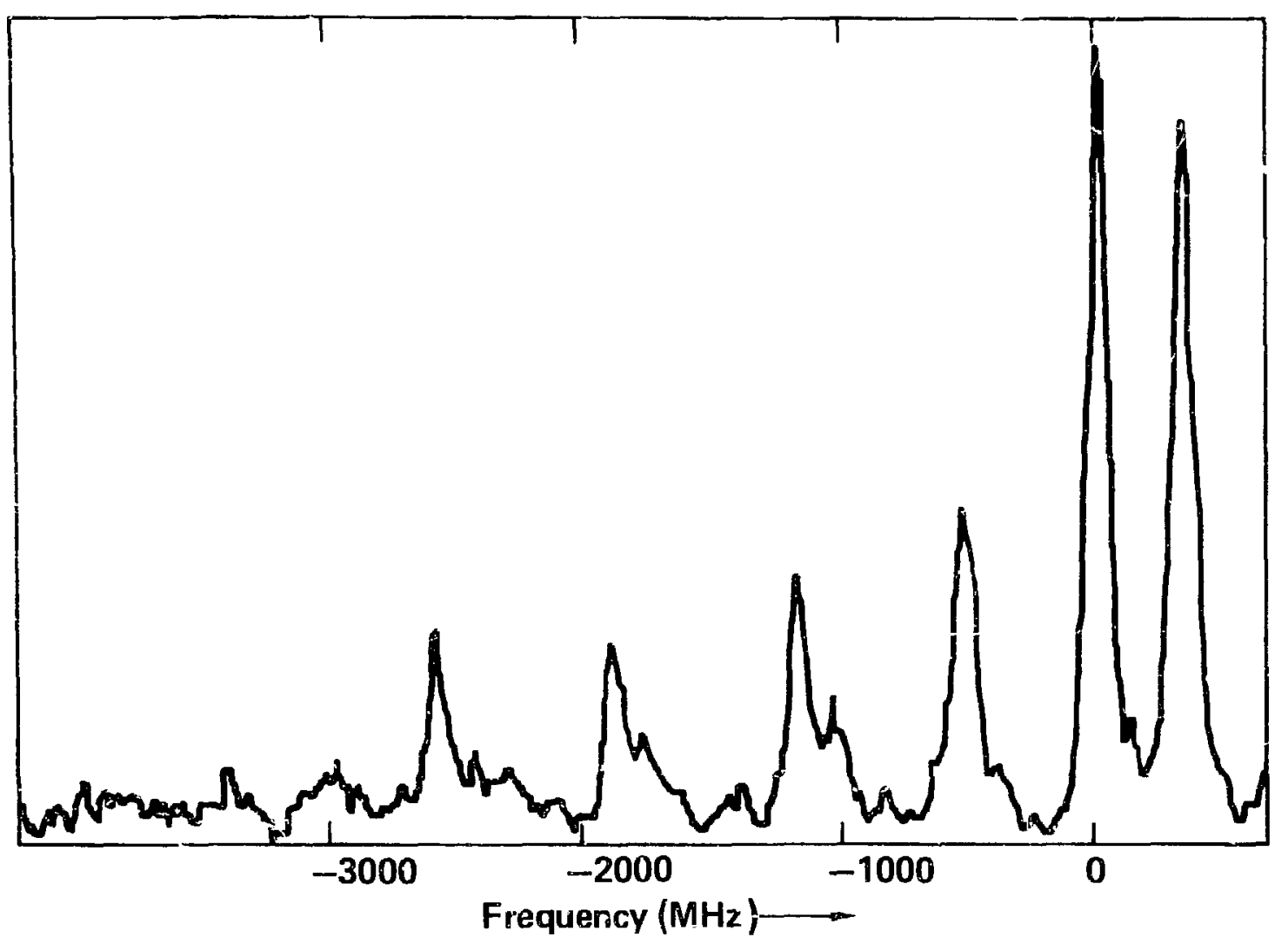

Figure 16. Hyperfine structure of $6156.8-\dot{A}\left(15,631\right.$ to $\left.31,859 \mathrm{~cm}^{-1}\right)$ transition in ${ }^{235} \mathrm{U}$.

Figure 18 summarizes the overall process concept. It shows that we use pump lasers [primarily copper-vapor lasers (CVLs) in the threestep process\} to energize a dye master oscillator. In an assembly we then use CVLs to energize dye amplifiers to achieve the required power levels. The final laser beam is injected into a separator containing a vapurizer, a product collector, and a tails collector. The product collector is illustrated schematically. There has been a great deal of work done on the collector both at LLNL and at Union Carbide Corporation in Oak Ridge, TN. The details of the collector are classified, but some general observations can be reported. The density in the individual separation zones is not what controls the throughput; it is controlled by the vapor-production rate at the vaporizer. The density in the extraction zone is controlled by the laser propagation and ion extractor physics.

Returning to the simple economic algorithm, where cost is divided into materia! processing and laser processing, Fig. 19 illustrates several relationships near the optimum density showing the scaling of cost for materials processing and lasers. Note that the laser costs do not decrease with increasing density but, in general, tend to increase aro ind the optimum. Thus there is ar optimum density and we want it neither toc high nor too low. Much effort has been expended to determine this optimum density.

To show the kinds of parameters relevant to this process, Fig. 20 summarizes the operating parameters for a large enrichment plant. It will typically proce: about $10^{7} \mathrm{~kg}$ of material per year (10,000 tonnes). For the AVLIS process the amount of laser energy required to illuminate $10^{7}$ $\mathrm{kg} /$ year can be easily estimated from the algorithm given earlier to be about $10^{-1} \mathrm{MJ} / \mathrm{kg}$. Multiplying these two numbers yields an estimate of the laser power of $30 \mathrm{~kW}$ of tunable power. That involves all three wavelengths properly controlled and other special operating conditions.

The following is a general description of the laser system. The laser architecture is generically a master-oscillator/power-amplifier (MOPA) configuration. The waveform generator consists of 


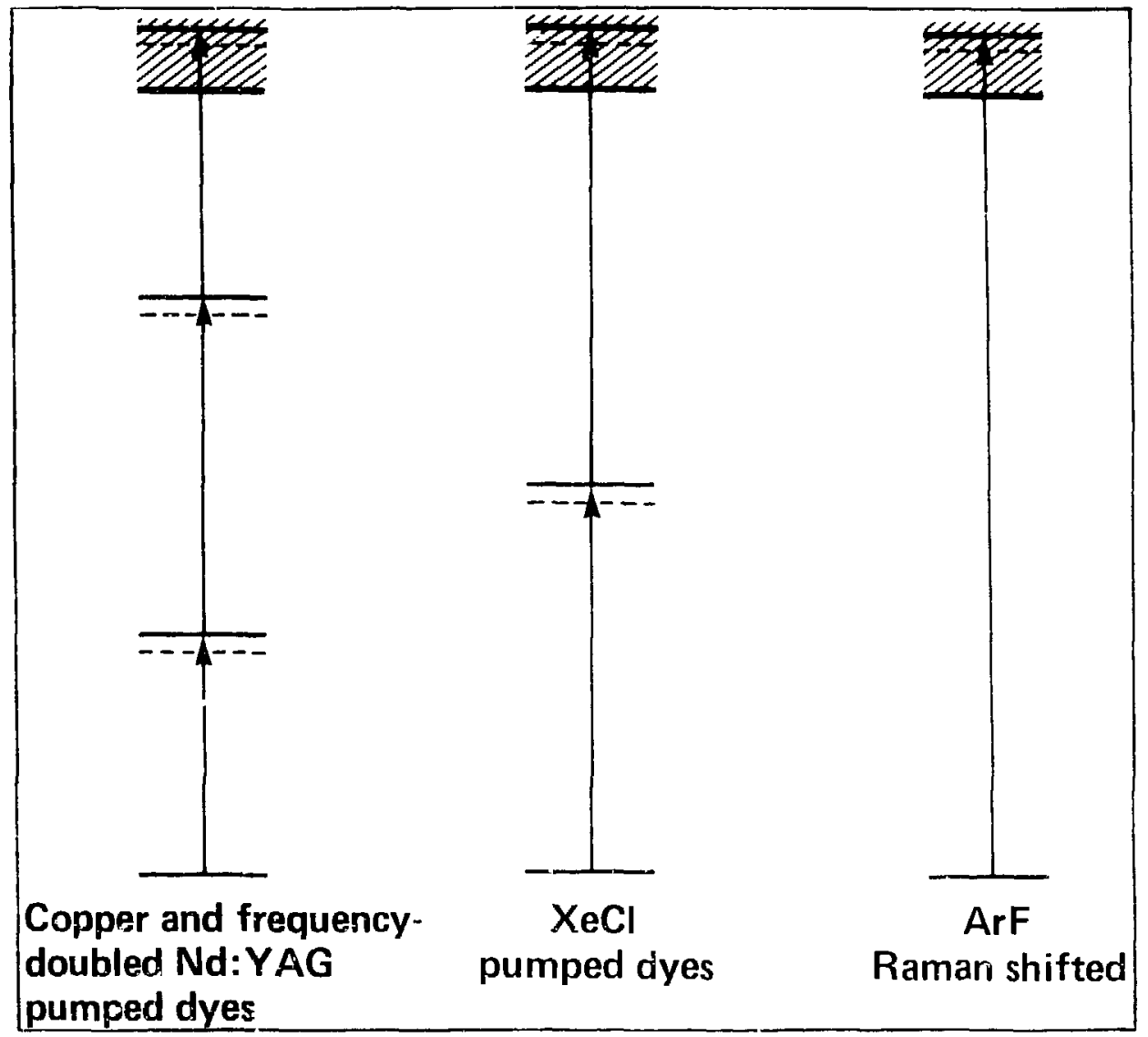

Figure 1\%. Laser photoionization options.

three basic waveform modules. Only one is shown in Fig. 21. The power is taken from the waveform module after the very fine frequency control is achieved in an oscillator. It is then preamplified after it has been locked on to the uranium transition. Then it goes into a main amplifier bank where the three different colors coming out of three different waveform modules are amplified, combined, and transmitted to the separation module. At LLNL we have built integrated facilities demonstrating this architectt:re (Fig. 22). We have a waveform generator and a poweramplifier module. There are 8 to $10 \mathrm{CVLs}$ accompanying the dye oscillators and the preamplifiers and there are 32 CVLs in the amplifier module to pump the dye amplifiers (Fig. 23). While this is a subscale laser system, it nevertheless has all the functions of a production plant, but operates at lower power. This complete functional demonstration is possible because of the MOPA architecture we have used. There is a low- throughput uranium separator and a highthroughput uranium separator next to the laser facility. We built the amplifier facility during 19771978 and have used it in large-scale separation experiments. Our plans involve building a similar type of amplifier module or modules but using larger CVL heads. Figure 24 illustrates how the CVL has evolved over the years. In 1975-1976, we were dealing with CVLs that would produce only 1-2 W of average power. In 1977 we were able to demonstrate CVLs with $10-20 \mathrm{~W}$ of average power. Then about 1980 we produced CVLs that generate $100-200 \mathrm{~W}$ of average power. Figure 25 shows a plant-scale laser in operation, producing in excess of $100 \mathrm{~W}$ of power in the green. These lasers are used in the MOPA configuration to energize dye oscillators and amplifiers. Figure 26 (a) shows one of the dye amplifiers with the green CVL pump beam. The red dye laser beam enters at one end and is amplified. Figure 26 (b) shows the dye flow and the way the beams are passing 


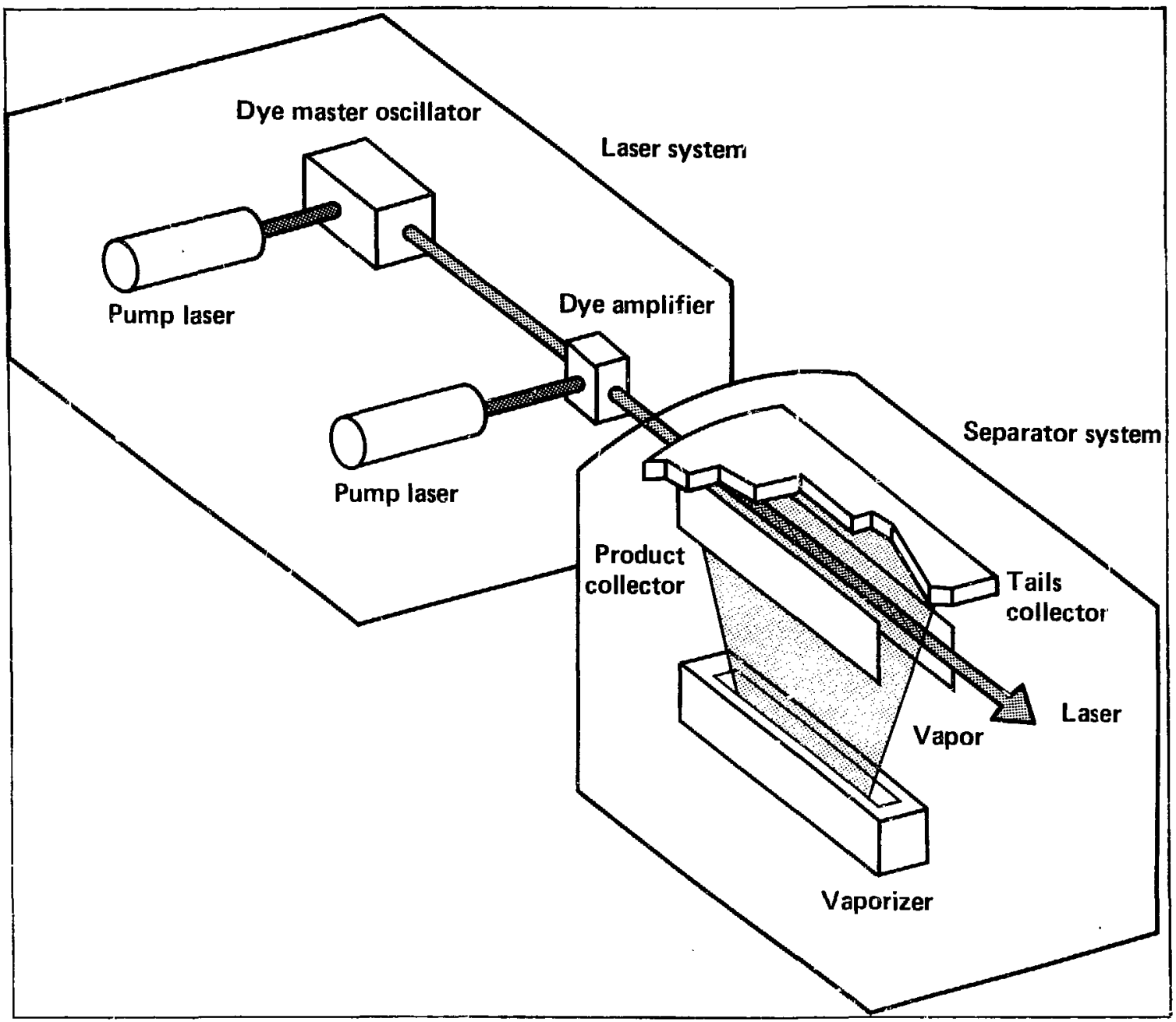

Figure 18. Schematic of AVLIS process.

through the interaction zone. The dye MOPA equipment is mounted on a special concrete support structure. Figure 27 shows a waveform module in an early phase of integration. The oscillator is at the back near the man and an amplifier is in the foreground. The oscillator and amplifier are mounted with rough accuracies and an autoalignment system is used to do the fine pointing of the beam.

With regard to metal processing, this has been a joint effort with the Union Carbide Cor- poration at Oak Ridge, TN. Figure 28 shows three uranium-metal processing chambers. The largest one is in the background and two smaller ones are in the foreground. The larger one began operation in 1977 and has been running now for 5 years. In 1977 this metal-handling technique was demonstrated, proving we could feed, vaporize, collect, and cast uranium in the chamber. Figure 29 shows 6 of the 50 to 100 uranium buttons produced in one run in 1977. 


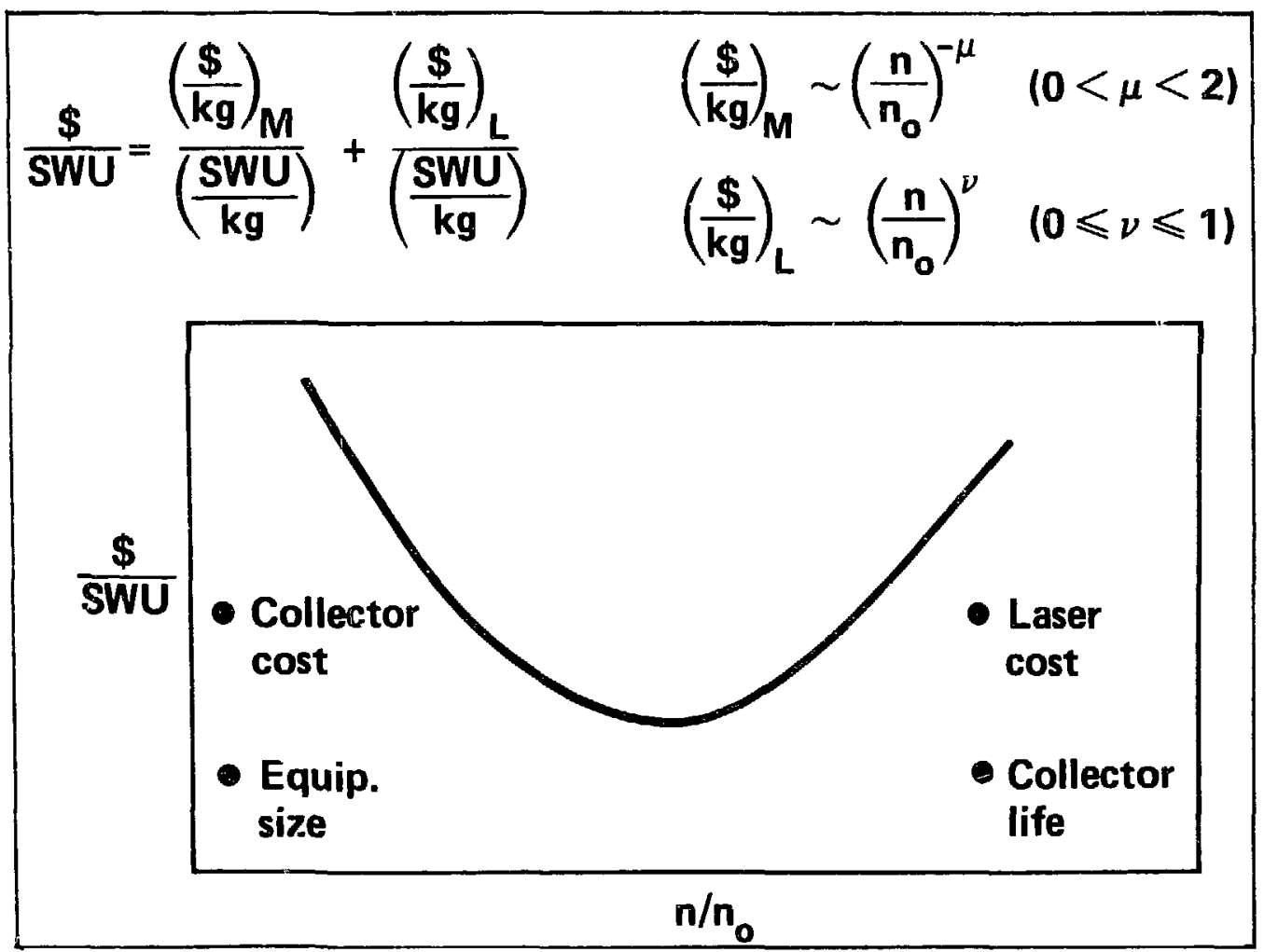

Figure 19. Some density-scaling phenomena.

$$
\begin{aligned}
& \dot{\mathrm{M}} \gtrsim 10^{7} \mathrm{~kg}_{\mathrm{F}} / \mathrm{yr} \\
& \frac{\mathrm{MJ}}{\mathrm{Kg}_{\mathrm{F}}} \leq 10^{-1} \\
& \overline{\mathrm{P}}_{\text {laser }} \sim 10^{6} \frac{\mathrm{MJ}}{\mathrm{yr}} \sim 3 \times 10^{4} \text { watts }
\end{aligned}
$$

Figure 20. AVLIS process requirements. 


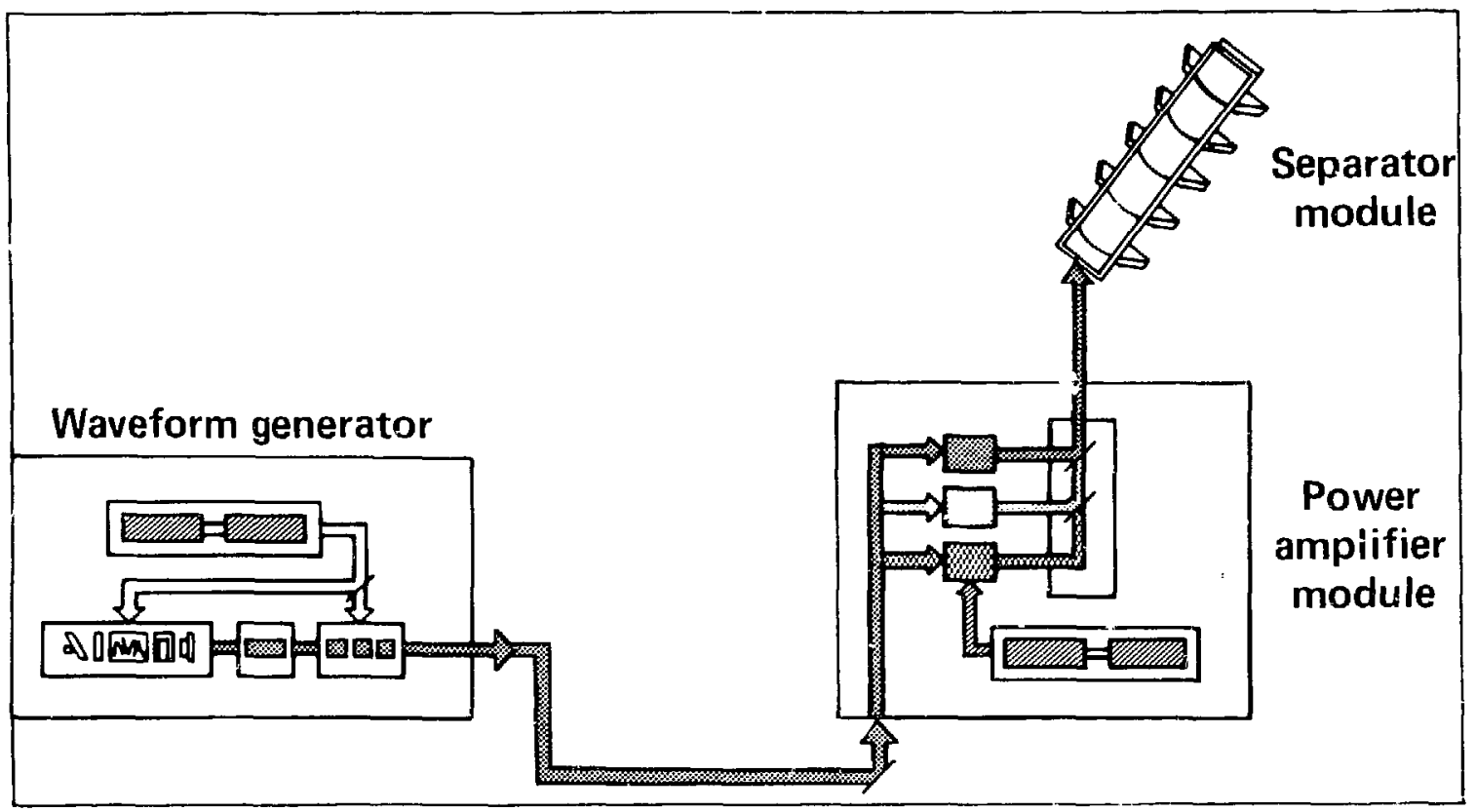

Figure 21. Development-module architecture.

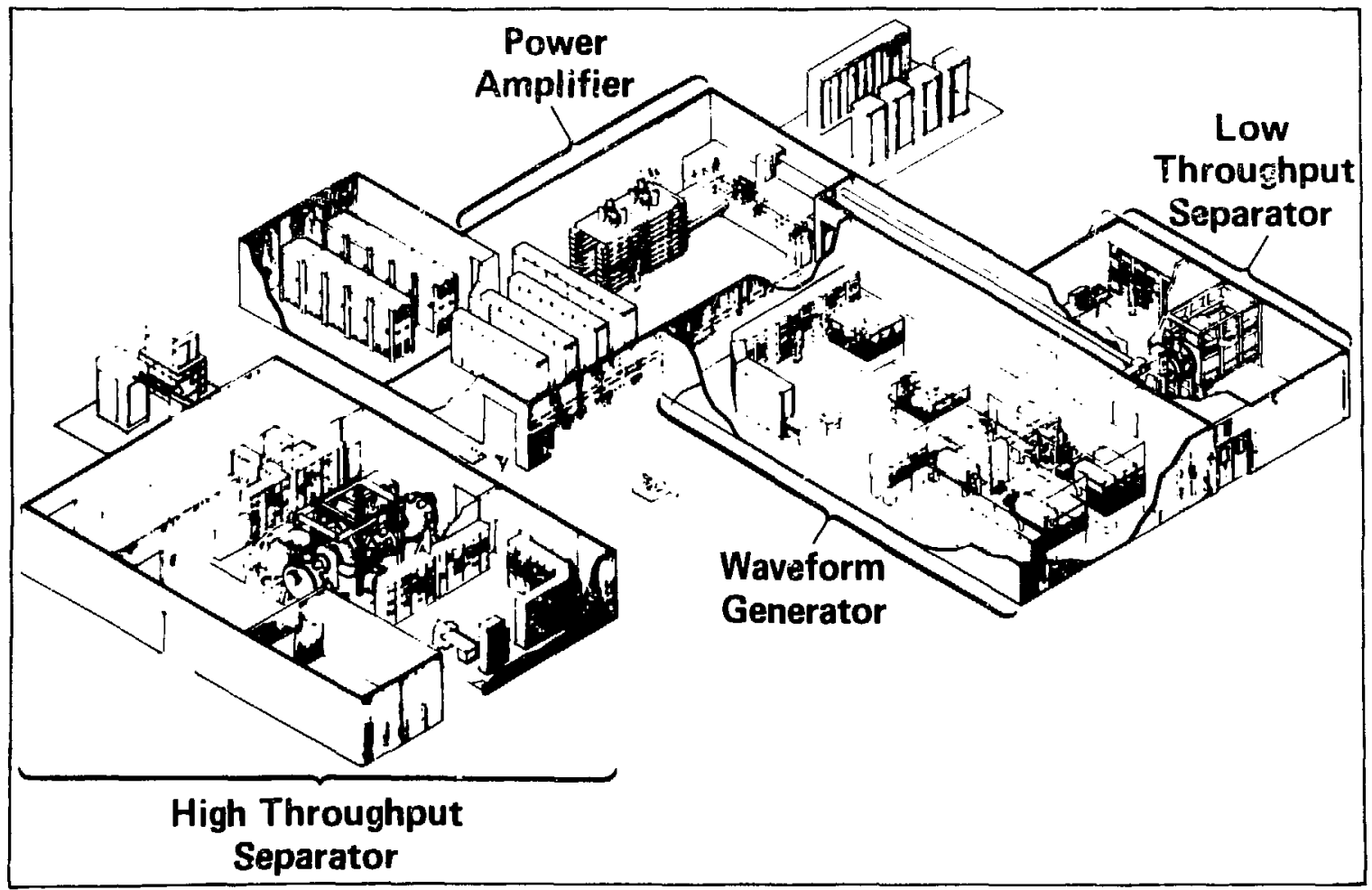

Figure 22. AVLIS test facilities. 


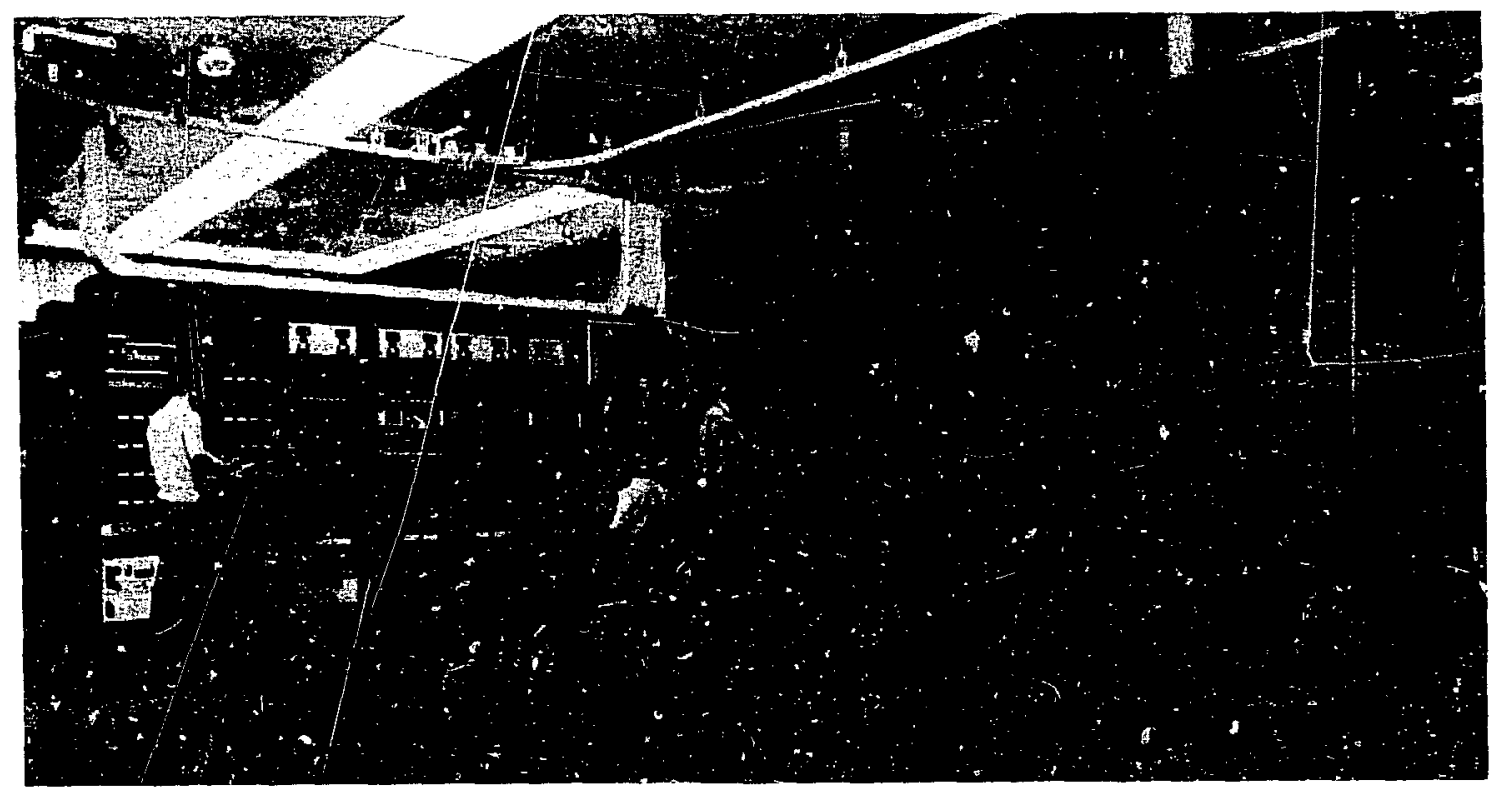

Figure 23. Sixteen of the $32 \mathrm{CVLs}$ used to pump the dye amplifiers.

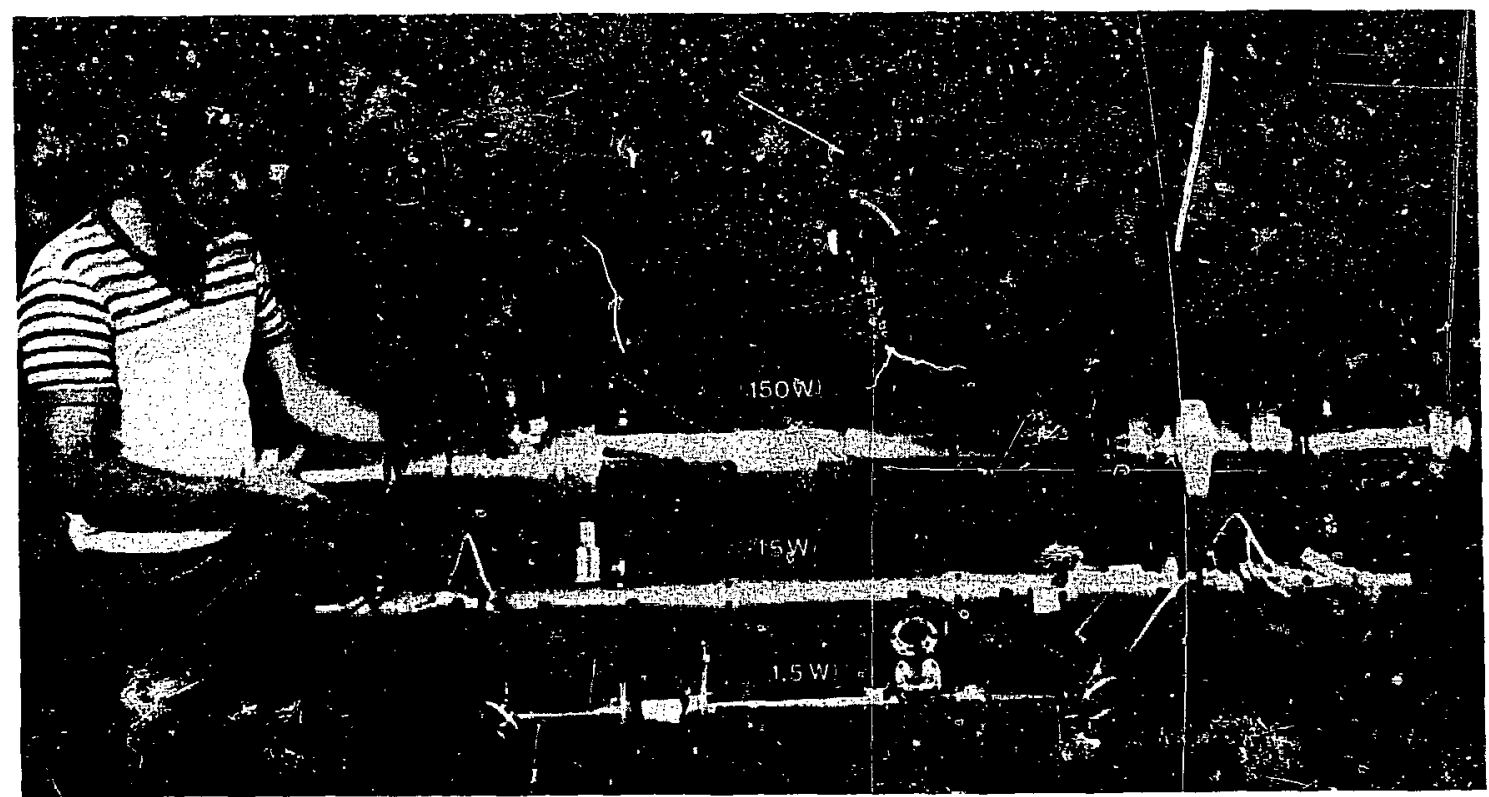

Figure 24. Evolution of CVLs from 1.5 to $150-\mathrm{W}$ average power. 


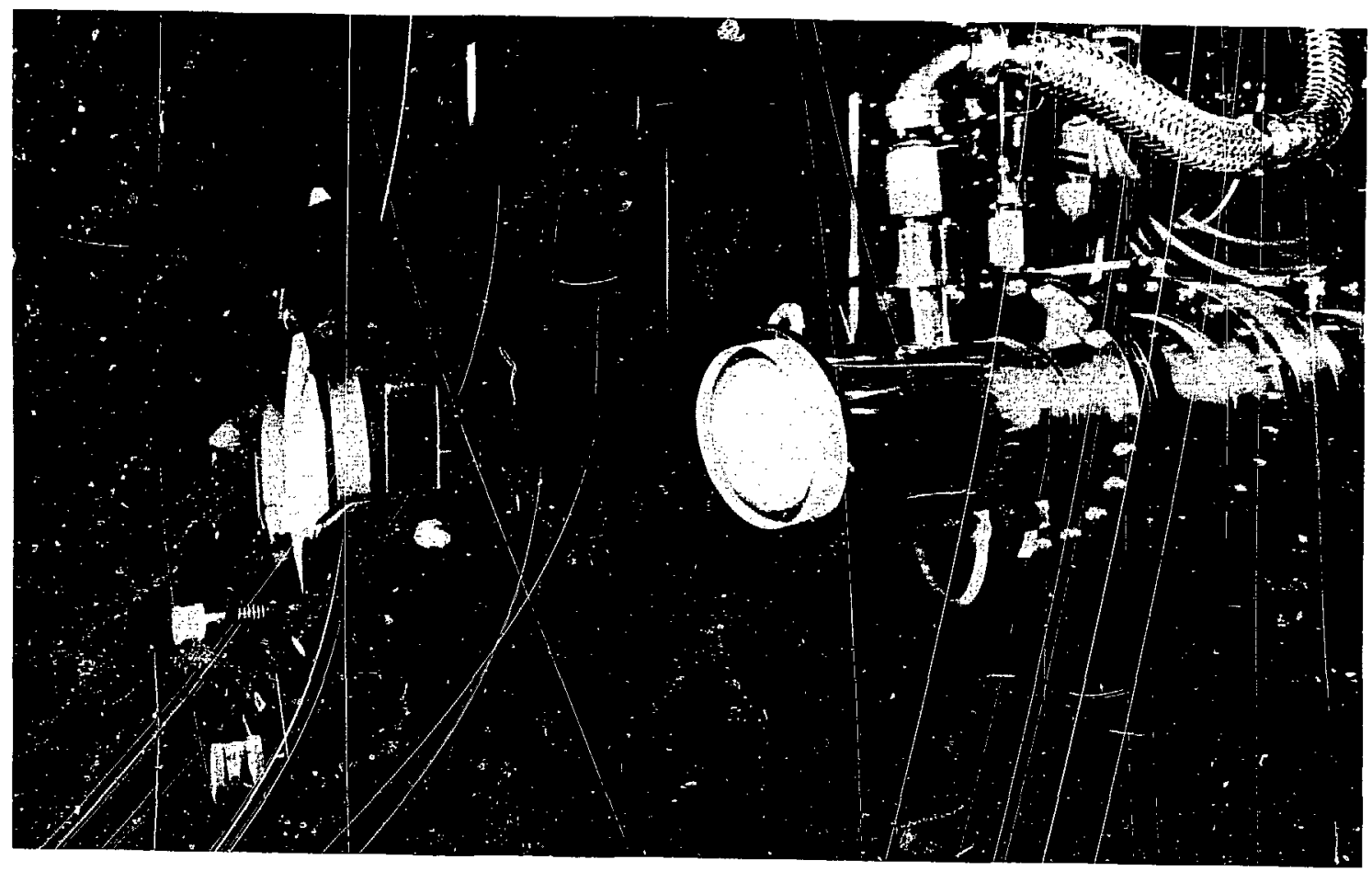

Figure 25. Plant-scale laser in operation.

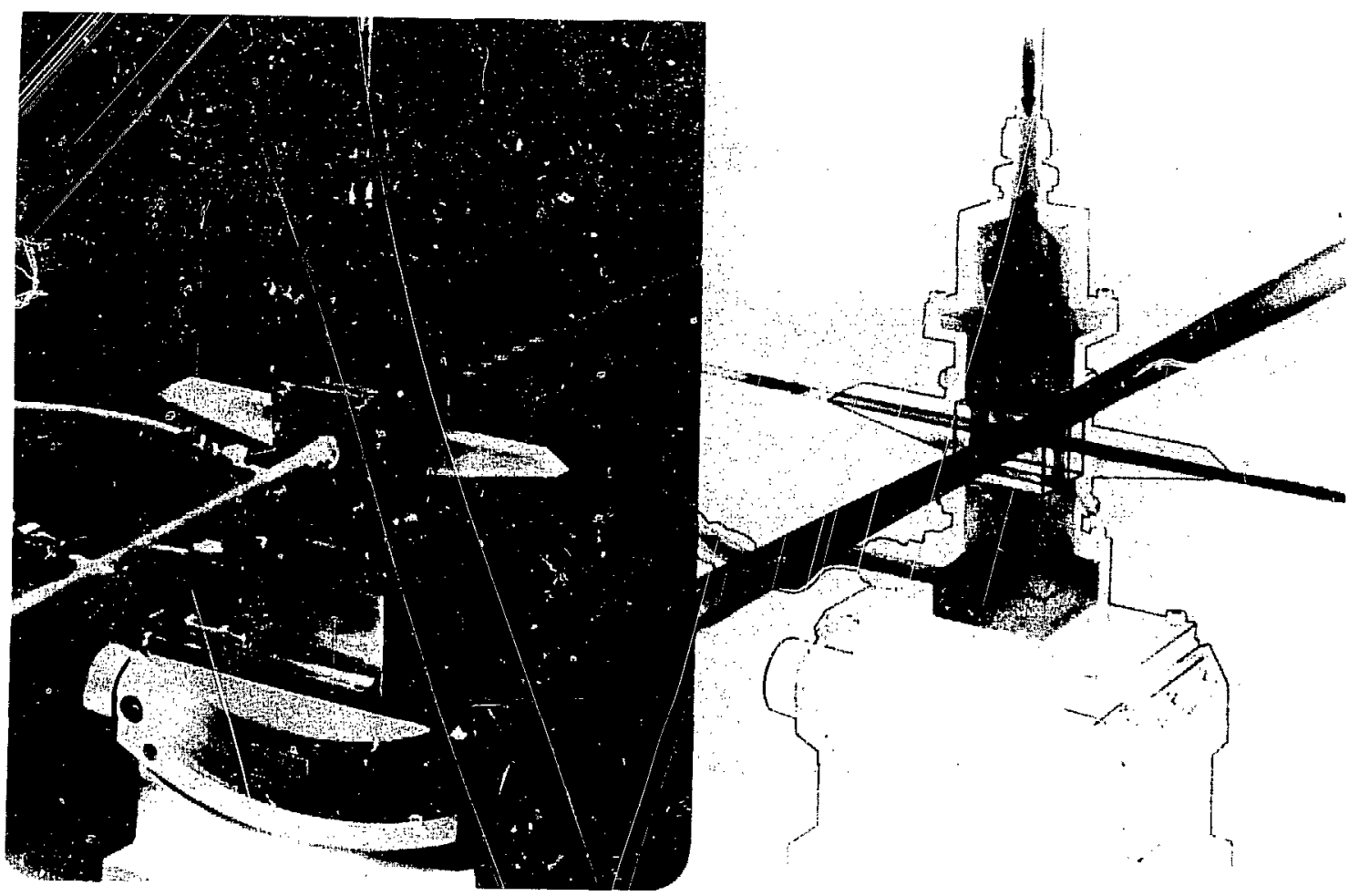

Figure 26. Dye amplifier. 


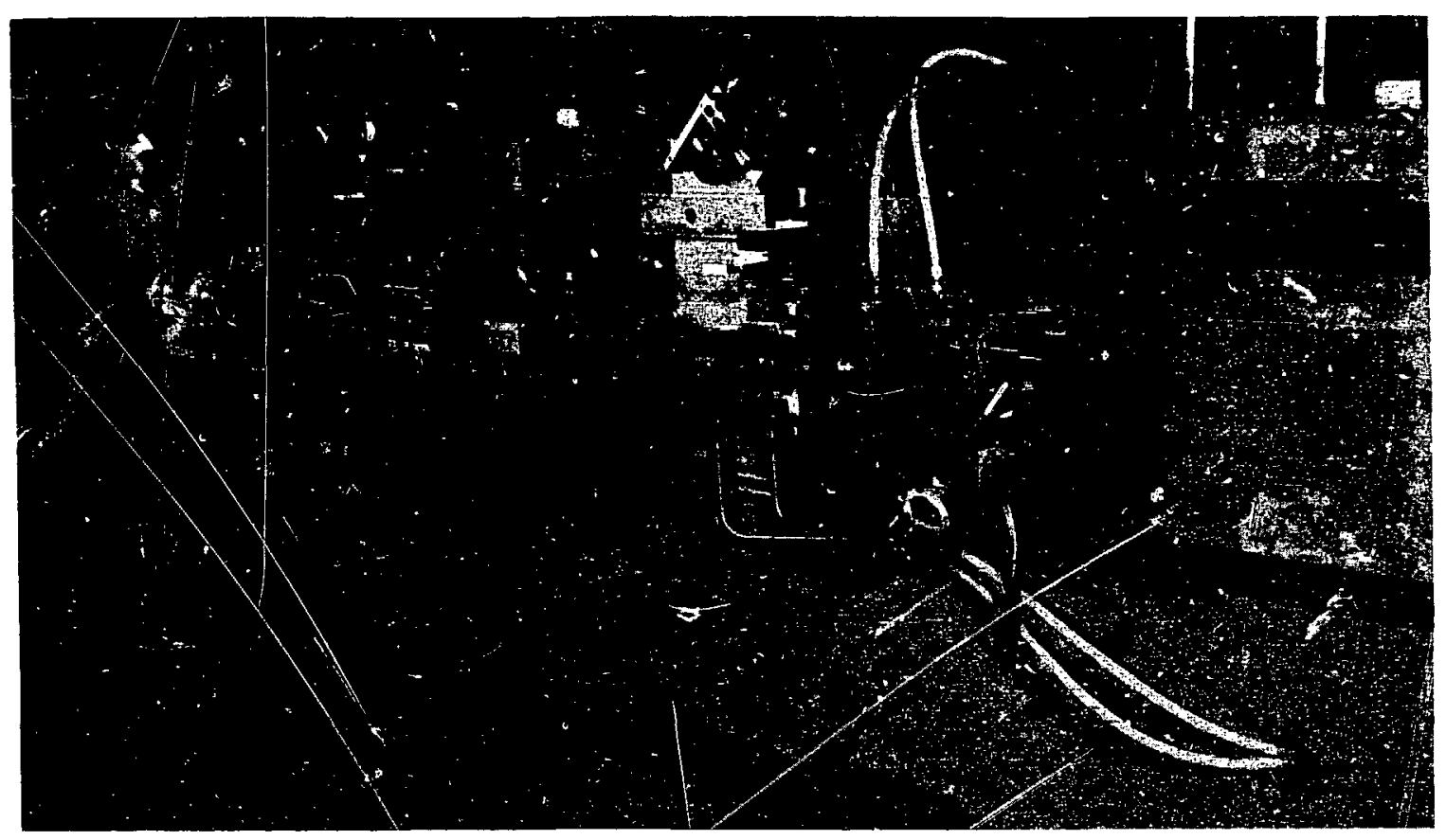

Figure 27. Waveform-module concrete support structure.

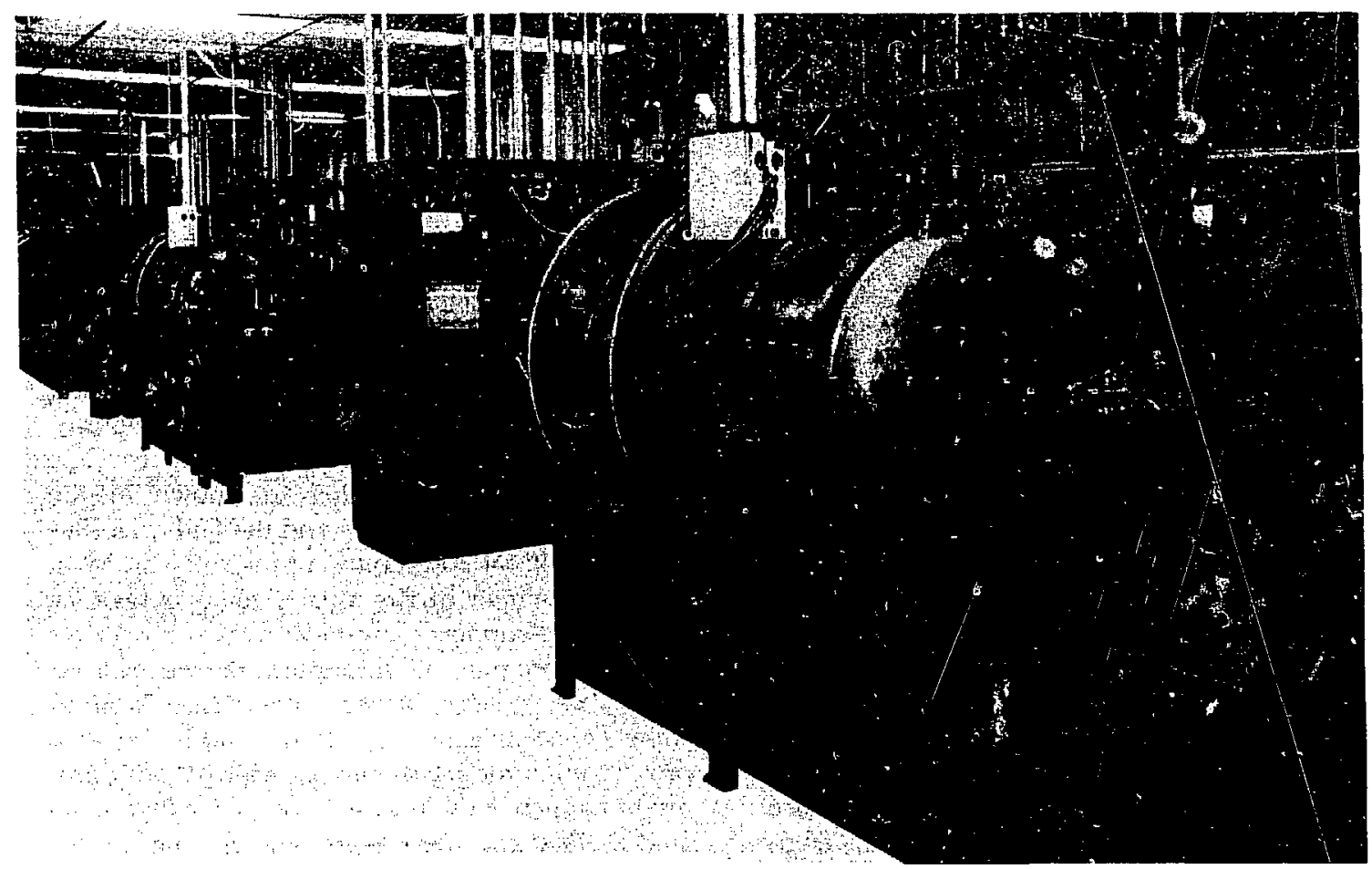

Figure 28. Uranium-metal processing at Oak Ridge. 


\section{Uranium Ingots. In 1977 uranium handling was demonstrated in an experimental AVLIS saparator system at UCCND. These $0.25-\mathrm{kg}$ uranium ingots were produced.}

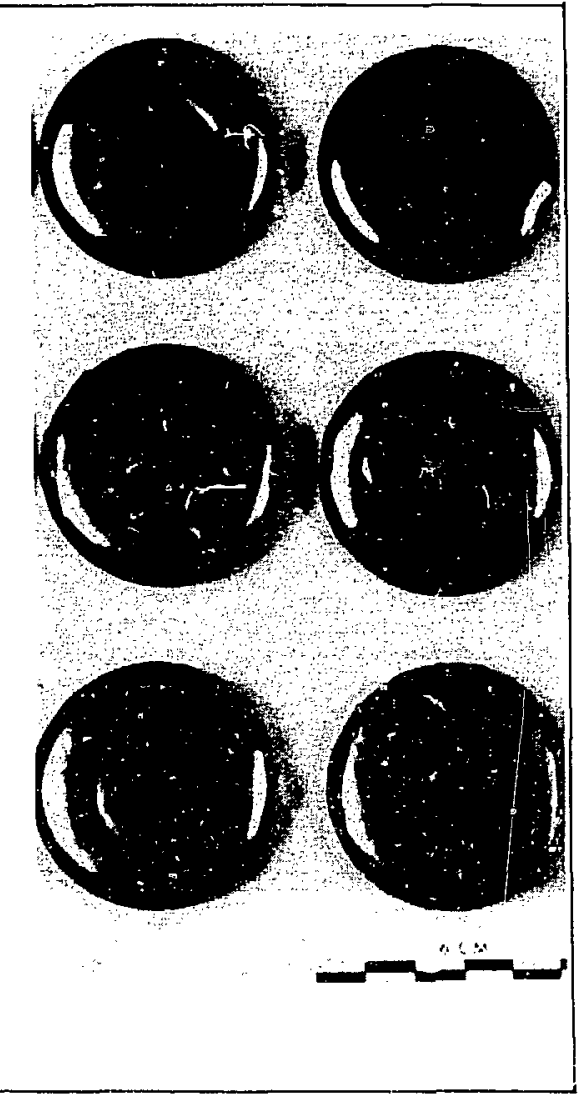

Fig̃ure 29. Uranium buttons produced during materials-handling demonstration.

\section{Future of L.IS}

At present the Department of Energy is considering the selection of a process and we have given them a schedule (Fig. 30 ) showing how we would develop our technology into a production unit in the 1990s. At LLNL we have the AIS facility (also known as the Technology Demonstration Facility) under construction. There is also an engineering demonstration (also known as the Development Module), which would begin construction in 1984 at Oak Ridge, TN. Eventually we would have a production facility at Oak Ridge in the 1990s. Figure 31 shows the AIS facility at LLINL. In the foreground is a laboratory facility of approximately $100,000 \mathrm{ft}^{2}$. The cutaway shows the CVL modules inside the facility; the high bay is for handling the uranium separator for the uraniummetal process. In the background is the office building of approximately $55,000 \mathrm{ft}^{2}$. The engineering demonstration will be at Oak Ridge, TN. Figure 32 is a model of that facility, showing the
CVLs on the left and the uranium separator on the right. The facility also contains all of the necessary maintenance and support equipment. The production plant is shown in Fig. 33 and we have gone through detailed conceptual designs for costing purposes. Figure 33 shows the layoui of the production plant of approximately $300,000 \mathrm{ft}^{2}$. The uranium separator modules are shown in the background of the cutaway and the CVL modules are shown in the foreground of the cutaway. Most of the remainder of the area is for maintenance and general-support equipment.

This program is important to the general application of lasers in chemistry. Figure 34 gives some perspective on how long it takes to get a process into production and shows what we think might happen in the future. Lasers were first operated in 1960 and there were tens of concepts for LIS and many other applications during the decade. The tunable dye laser was first operated in 


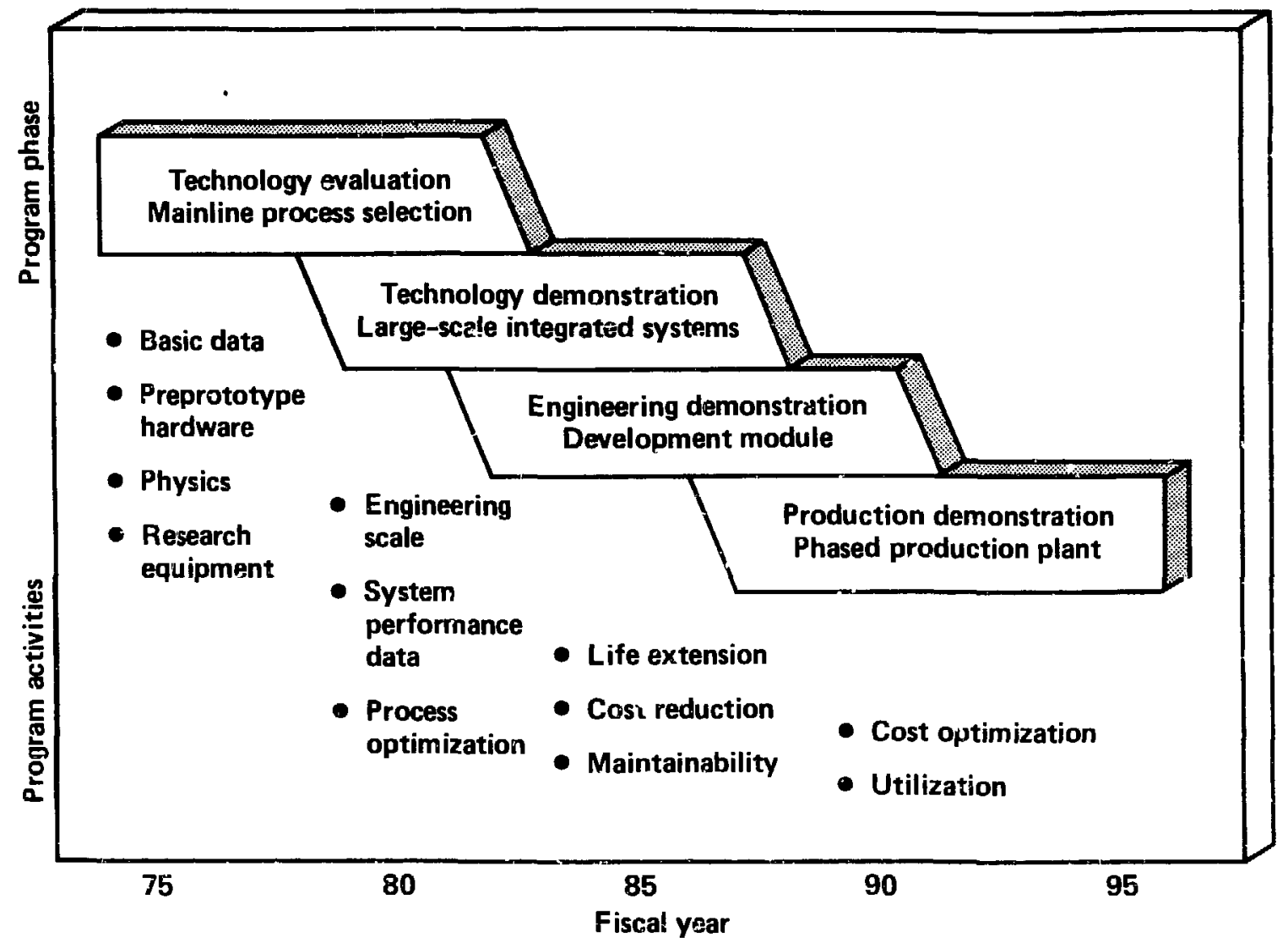

Figure 30. AVLIS program develupment phases.

the late 1960s and that enhanced the prospects for using lasers in chemical applications. Scientific feasibility for uranium LIS was done in the early 1970s. There were also a lot of evaluations of the tens of LIS processes. Severe economic analyses were performed and we are now approaching a period of decision where we will go into a very intensive engineering effort. We believe we will see in the next decade a much more orderly scientific evaluation of industrial photochemistry. There was a certain amount of euphoria in the 1970 s that is beginning to wear off, but we believe there will be enough major applications of lasers once they have undergone careful examination and there will be more fruitful research in the 1980 s. We can expect in the 1990s to see industrial photochemistry emerge. This is why we think this program is so important. It will be the first real use of lasers on a large industrial scale and we believe it will help the general acceptance of laser technology by the chemical industries and the general acceptance across the board of laser technology in commercial processes. 


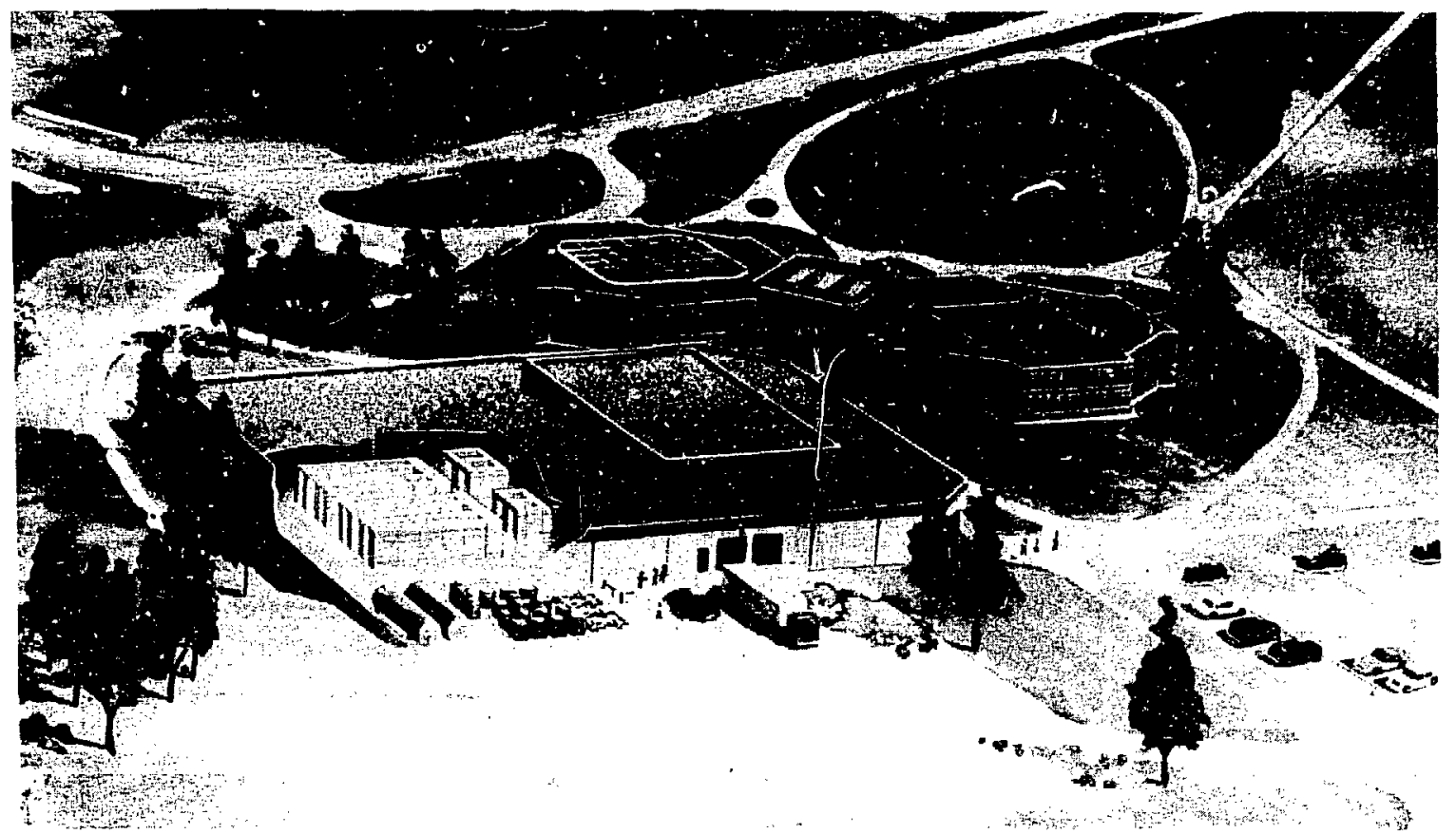

Figure 31. AIS facility at LLNL.

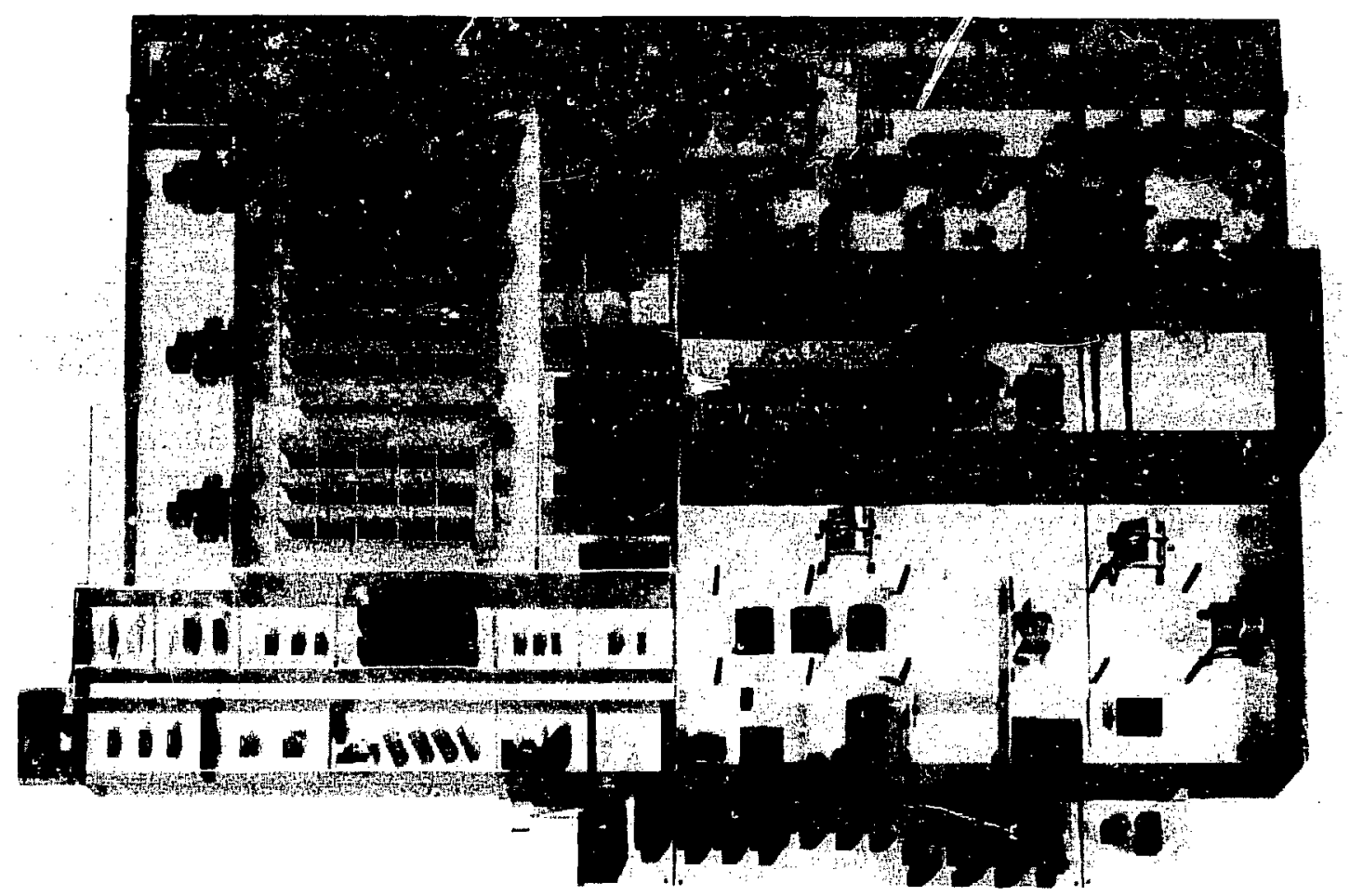

Figure 32. Model of Development Module to be built at Oak Ridge, TN. 


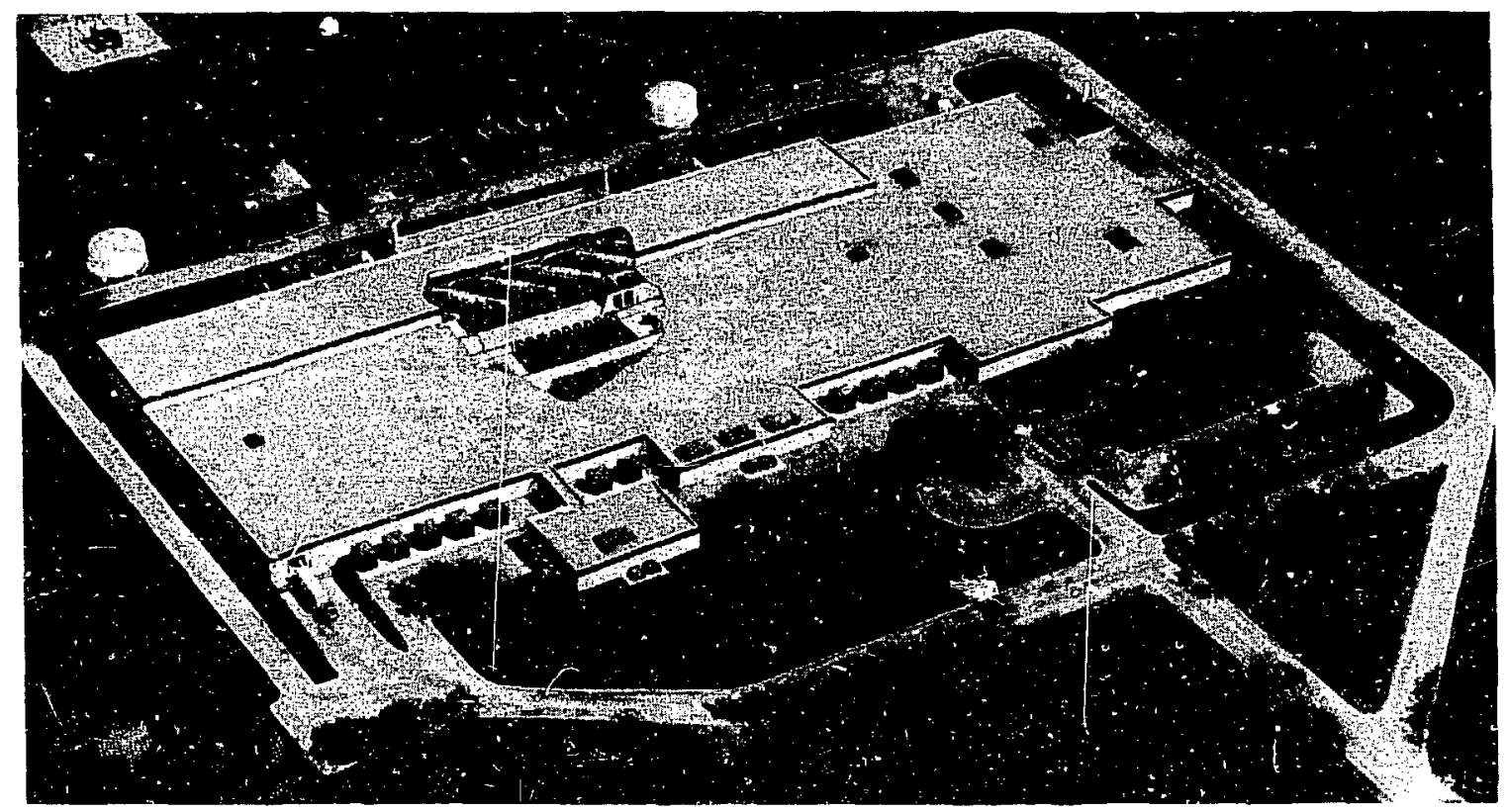

Figure 33. AVLIS production plant.

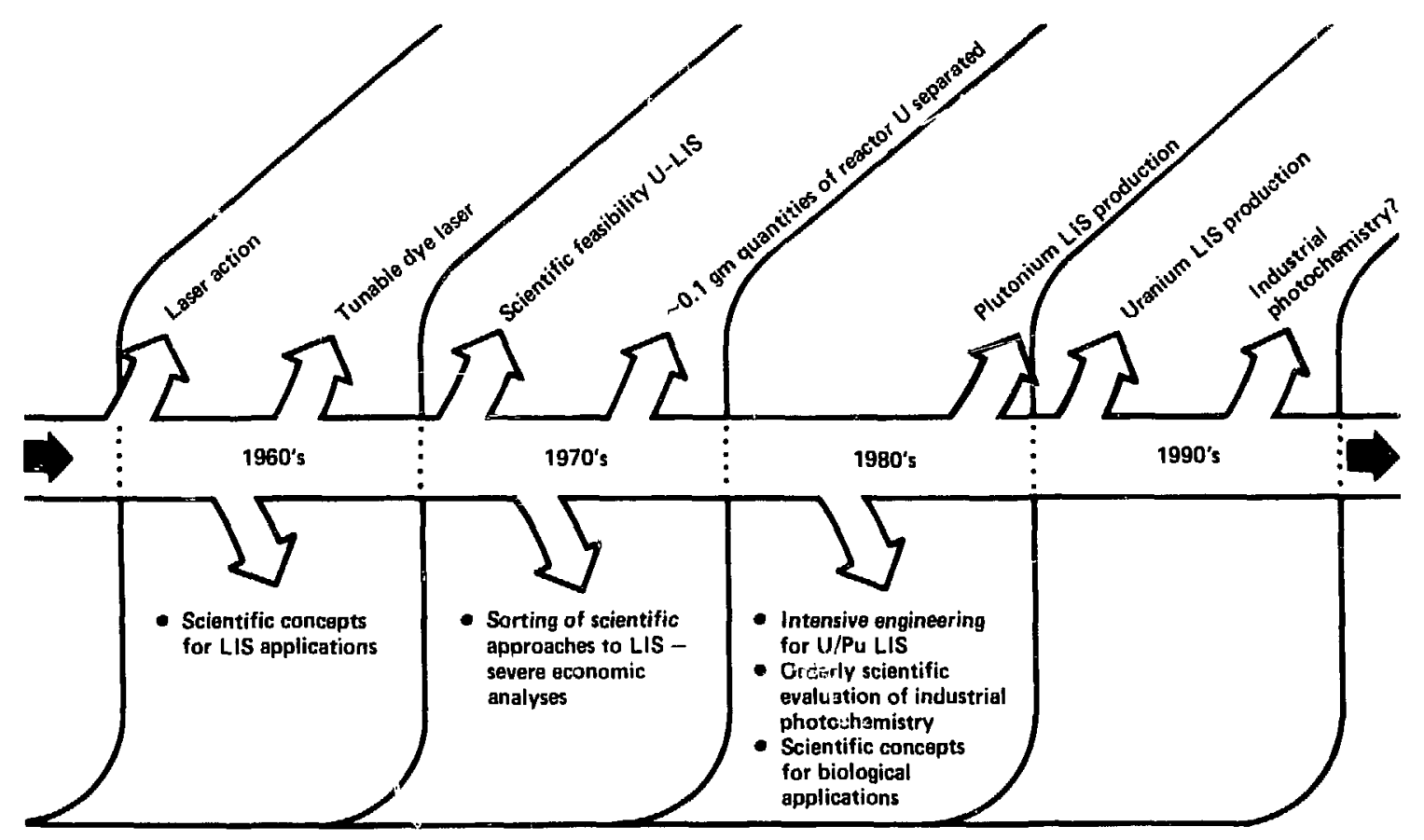

Figure 34. Projections of science, technology, and applications. 


\section{References}

1. See, for example, "The Laser-A Future Tool for the Chemical Industry," Chem. Eng. News, New Technology Supplement, December 22, 1980.

2. C. B. Moore, Am. Assoc. Advan. Sci. Annual Meeting, Washington, D.C. (1977).

3. W. Happer et al., "Laser Induced Photochemistry," JASON Report JSR-78-11, SRI International, Stanford, CA (1979). 